\title{
Targeting S100B in Cerebral Ischemia and in Alzheimer's Disease
}

\author{
Takashi Mori, ${ }^{1,2}$ Takao Asano, ${ }^{1}$ and Terrence Town ${ }^{3,4,5}$ \\ ${ }^{1}$ Department of Biomedical Sciences, Saitama Medical Center and University, 1981 Kamoda, Kawagoe, Saitama 350-8550, Japan \\ ${ }^{2}$ Department of Pathology, Saitama Medical Center and University, 1981 Kamoda, Kawagoe, Saitama 350-8550, Japan \\ ${ }^{3}$ Department of Biomedical Sciences, Regenerative Medicine Institute, Cedars-Sinai Medical Center, 8700 Beverly Boulevard, \\ Los Angeles, CA 90048, USA \\ ${ }^{4}$ Department of Neurosurgery, Maxine Dunitz Neurosurgical Institute, Cedars-Sinai Medical Center, 8700 Beverly Boulevard, \\ Los Angeles, CA 90048, USA \\ ${ }^{5}$ Department of Medicine, David Geffen School of Medicine, University of California, Los Angeles, 8700 Beverly Boulevard, \\ Los Angeles, CA 90048, USA
}

Correspondence should be addressed to Takashi Mori, t_mori@saitama-med.ac.jp and Terrence Town, terrence.town@cshs.org

Received 31 March 2010; Revised 25 June 2010; Accepted 20 July 2010

Academic Editor: Rosario Donato

Copyright (c) 2010 Takashi Mori et al. This is an open access article distributed under the Creative Commons Attribution License, which permits unrestricted use, distribution, and reproduction in any medium, provided the original work is properly cited.

\begin{abstract}
S100B is an EF-hand calcium-binding protein that exerts both intracellular and extracellular effects on a variety of cellular processes. The protein is predominantly expressed in the central nervous system by astrocytes, both physiologically and during the course of neurological disease. In the healthy adult brain and during development, constitutive S100B expression acts as a trophic factor to drive neurite extension and to referee neuroplasticity. Yet, when induced during central nervous system disease, the protein can take on maladaptive roles and thereby exacerbate brain pathology. Based on genetic and pharmacological lines of evidence, we consider such deleterious roles of S100B in two common brain pathologies: ischemic stroke and Alzheimer's disease (AD). In rodent models of ischemic brain damage, S100B is induced early on during the subacute phase, where it exacerbates gliosis and delayed infarct expansion and thereby worsens functional recovery. In mouse models of AD, S100B drives brain inflammation and gliosis that accelerate cerebral amyloidosis. Pharmacological inhibition of S100B synthesis mitigates hallmark pathologies of both brain diseases, opening the door for translational approaches to treat these devastating neurological disorders.
\end{abstract}

\section{Introduction}

The principal cell types comprising the brain parenchyma are neurons and glial cells. The term "glia" is customarily used to refer to neuroglia (comprised of astrocytes, oligodendrocytes, and more recently, NG2 oligodendrocyte progenitors), Schwann cells, and central nervous system- (CNS-) resident macrophages known as microglia. Occasionally, ependymal cells (ependymoglia) are also classified as glia, as they are differentiated from radial glia [1] and share astrocytic properties [2]. In addition to parenchymal cells, cerebral vascular cells exist and form a physiological barrier in the CNS known as the blood-brain barrier (BBB). Among these cellular constituents, astrocytes greatly outnumber neurons in the brain, making up about $50 \%$ of human brain volume [3]. Despite the time-honored concept that astrocytes are "silent partners of the working brain", accumulating evidence has shown that astrocytes are active participants in CNS physiology [4-6], including transport of substances between blood and neurons $[3,4]$, cerebral blood flow metabolism control [7-10], modulation of synaptic transmission [1113], synaptogenesis [14-18], and neurogenesis [19-22].

Yet, astrocytes are capable of directly endangering neurons during the course of inflammatory CNS disorders [23, 24]. In fact, acute and chronic CNS disorders often have a component of glial activation, characterized by infiltration of activated microglia and astrocytes into the region of damaged tissue [21, 25-28]. Reactive astrocytes likely exert their effects in collaboration with activated microglia. On the one hand, these cells may exacerbate neuroinflammation by producing a myriad of toxic substances, including cytokines, nitric oxide, prostanoids, and reactive oxygen species; on the other hand, they are capable of exerting beneficial effects by producing neurotrophic substances [3-6, 21, 25, 29, 30]. Much recent attention has been focused on this enigmatic duality so often observed in studies of activated glia within 
the broader context of neurological and neurodegenerative diseases.

This paper begins by addressing the double-edged sword of both beneficial and detrimental actions of astrocytic S100B in the CNS. Subsequently, we move on to focus on contributions of reactive astrocytes to glial inflammatory responses in two common neurodegenerative diseases: cerebral ischemia and Alzheimer's disease (AD). Finally, we consider the concept of translating S100B inhibition to the clinic for the treatment of neurodegenerative diseases.

\section{Beneficial and Detrimental Actions of S100B in the Central Nervous System}

S100 is a large family (over 20 members) of EF-hand (helix E-loop-helix F) calcium-binding proteins, and all but four are clustered on human chromosome 1q21, while the human gene encoding S100B maps to chromosome 21q22 [31-38]. A total of ten $S 100$ family members are expressed in the brain, including S100A1, S100A2, S100A4, S100A5, S100A6, S100A10, S100A11, S100A13, S100B, and S100Z. In addition, mRNA levels of S100A1/S100B are 5fold higher than S100A6/S100A10 and 100-fold higher than S100A4/S100A13 in the mouse brain. Five of these six family members (S100A1, S100A6, S100A10, S100A13, and S100B) are increased in an age-dependent manner in adult mice [39]. $\mathrm{S} 100 \mathrm{~B}$ is detected in varying abundance in a limited number of brain cells including astrocytes, maturing oligodendrocytes, neuronal progenitor cells, pituicytes, ependymocytes, and certain neural populations. Although the majority of astrocytic S100B localizes within the cytoplasm, $5 \%-7 \%$ is membrane bound [32, 34, 38, 40-42]. S100B has been implicated in $\mathrm{Ca}^{2+}$-dependent regulation of a variety of intracellular functions such as protein phosphorylation, enzymatic activity, cell proliferation and differentiation, cytoskeletal dynamics, transcription, structural organization of membranes, intracellular $\mathrm{Ca}^{2+}$ homeostasis, inflammation, and protection against oxidative damage [31-38, 43-46].

Binding of S100B to receptors on target cells releases intracellular free $\mathrm{Ca}^{2+}$ from $\mathrm{Ca}^{2+}$ stores via activation of phospholipase $\mathrm{C}$ and downstream inositol triphosphate [43]. As overexpression of $\mathrm{S} 100 \mathrm{~B}$ induces downregulation of p53 protein [47], calcium signaling and S100B may act in cooperation with this pathway, which is implicated in growth inhibition and apoptosis [47-49]. Yet, how elevation of cytosolic $\mathrm{Ca}^{2+}$ transduces S100B binding into trophic and proliferative effects on brain cells is still elusive.

During brain development, a temporal correlation has been reported between synaptogenesis and astrocyte differentiation [50]. Numerous findings support the notion that astrocytes regulate the formation, maturation, and maintenance of synapses [14-17]. Astrocytic S100B expression increases in the rodent brain during the first 3 postnatal weeks-a critical period for glial proliferation and synaptogenesis, and it was suggested nearly 40 years ago that the protein likely referees synaptic development in vivo [51,52]. In the adult rodent brain, S100B expression persists at nanomolar concentrations and likely orchestrates neurite extension [53], enhances survival of neurons and promotes synapse formation [54], and exerts protective actions after injury $[55,56]$.

On the other hand, there is accumulating evidence that S100B may also have detrimental actions in the CNS. Activation of microglia triggers and promotes astrocytic activation through release of cytokines such as tumor necrosis factor$\alpha($ TNF- $\alpha)$ and interleukin- $1 \beta$ (IL- $1 \beta)$. These and other cytokines drive a synergistic relationship between these two types of glial cells via a vicious positive feedback loop known as the "cytokine cycle" [24]. While numerous bioactive substances are part and parcel of this cycle, S100B can be regarded as a major constituent of this brain-damaging feedback loop. In this context, $\mathrm{Hu}$ and colleagues demonstrated that $\mathrm{S100B}$ at micromolar concentrations induces neuronal damage in a neuron and astrocyte coculture experiment by causing overexpression of inducible nitric oxide synthase and subsequent release of nitric oxide [57]. Lam and colleagues showed that S100B stimulates inducible nitric oxide synthase in rat primary cortical astrocytes through a signal transduction pathway that involves activation of the transcription factor nuclear factor- $\kappa \mathrm{B}(\mathrm{NF}-\kappa \mathrm{B})$, which is a master regulator of pro-inflammatory responses [58]. $\mathrm{Hu}$ and Van Eldik showed that S100B upregulates IL- $1 \beta$ expression in astrocytes [59], and Ponath and coworkers showed that S100B stimulates release of IL- 6 and TNF- $\alpha$ from astrocytes [60].

Importantly, numerous secreted S100 proteins (S100B, S100A1, S100A2, S100A4, S100A5, S100A6, S100A7, S100A8/ A9, S100A11, S100A12, and S100P) can act in either an autocrine or paracrine fashion through a common receptor: the receptor for advanced glycation endproducts (RAGE), a multiligand receptor that belongs to the immunoglobulin family. Moreover, in cell-based assays, all these family members (except for S100A2 and S100A5) have been shown to trigger RAGE-dependent signaling [38, 61-65]. The fact that the RAGE promoter has functional NF- $\kappa \mathrm{B}$ binding sites reinforces the likelihood that this signaling pathway is an important trigger of inflammatory pathogenesis [66]. Moreover, it has been shown that RAGE and S100/calgranulin signaling propagate, recruit, and activate cellular pro-inflammatory effectors [61]. Accordingly, nanomolar concentrations of extracellular S100B can trigger expression of the anti-apoptotic factor Bcl-2 in RAGEexpressing cells, whereas micromolar $\mathrm{S100B}$ concentrations induce apoptosis via RAGE activation [67]. In primary microglia, S100B stimulates IL- $\beta$ production by activating extracellular signal-regulated kinase 1/2 (ERK1/2), p38 mitogen-activated protein kinase (p38 MAPK), and c-Jun $\mathrm{NH}_{2}$ terminal protein kinase (JNK) [68]. There is evidence that S100B-mediated microglial pro-inflammatory responses are RAGE-dependent, as RAGE ligation by S100B induces expression of the pro-inflammatory enzyme cyclooxygenase2 (COX-2) via parallel Ras-Cdc42-Rac1-dependent activation of JNK and Ras-Rac1-dependent stimulation of NF- $\kappa \mathrm{B}$ transcriptional activity. Further, S100B engagement of RAGE coordinately stimulates NF- $\kappa \mathrm{B}$ and $\mathrm{AP}-1$ transcriptional activity and synergizes with IL- $1 \beta$ and TNF- $\alpha$ to upregulate COX-2 expression [65]. 


\section{Reactive Astrocytes and S100B in Cerebral Ischemia}

While there is a wide spectrum of various forms of brain damage, ischemic stroke (cerebral ischemia) is the most prevalent type of brain injury that causes death and longlasting disability. The pathogenic effects of microcirculatory dysfunction in cerebral ischemia can be divided into two categories: impairment of intraluminal cerebral blood flow and extraluminal effects resulting from alterations in the $\mathrm{BBB}$ [69]. Over the past decade, extensive research efforts have been directed toward development of neuroprotective drugs against cerebral ischemia, such as ion channel antagonists, glutamate receptor antagonists, and free radical scavengers. Anti-platelet drugs, anti-thrombotic drugs, tissue plasminogen activators, and free radical scavengers have already come into routine clinical use and clinical trials investigating additional agents are ongoing.

In the clinical setting, S100B is a well-known biomarker that positively associates with severity of brain damage and has been shown to predict prognosis after subarachnoid hemorrhage $[70,71]$, ischemic brain injury $[72,73]$, and traumatic brain injury [74]. It is important to note that the above clinical studies are correlative in nature and presume that rise in cerebral spinal fluid and serum concentrations of $\mathrm{S} 100 \mathrm{~B}$ is due to release of intracellular stores of the protein upon cellular disruption. Thus, the possibility that S100B is synthesized de novo by reactive astrocytes and exacerbates infarct evolution was not considered in these reports. In addition, a surge of attention from both physiological and therapeutic standpoints has been directed toward the possible roles of astrocytes in neurometabolic and neurovascular coupling.

After focal cerebral ischemia, brain damage is accompanied by infiltration of reactive astrocytes into the periinfarct area. Specifically, astrocytes are copiously activated along the outer border of the infarct. Reactive astrocytes are earmarked by increased expression of S100B and glial fibrillary acidic protein (GFAP), appear around 24 hours after the onset of ischemia, and undergo hypertrophy and hyperplasia for a period of weeks thereafter [75-77]. During the chronic disease phase ( $>168$ hours post-ischemia), astrocytes extensively wall off the BBB at the glial limitans [78] (Figure 1), participate in angiogenesis concurrent with development of cerebral edema $[29,79]$, and possibly drive neurogenesis $[19,22]$. On the other hand, when considering the subacute phase (24-168 hours after ischemia onset) of this neurological disorder, it has been difficult to assign a role to reactive astrocytes. This is owed to the long-held belief that infarct expansion after focal cerebral ischemia comes to a complete halt by 12 hours, well before astrocytic activation manifests [80]. However, "delayed infarct expansion" during the subacute phase of cerebral ischemia was later discovered and is now becoming generally accepted. This pathological event has led to a wider recognition of the possible detrimental role of astrocytic activation in the subacute phase of cerebral infarction as a valid research target [81].

With regard to the concept of delayed infarct expansion, Garcia and colleagues used the rat permanent focal cerebral

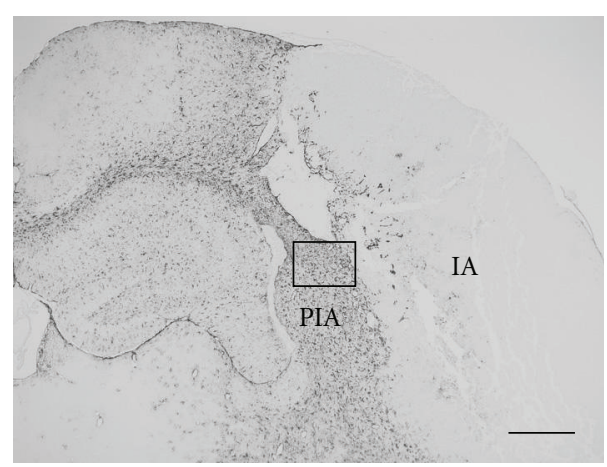

(a)

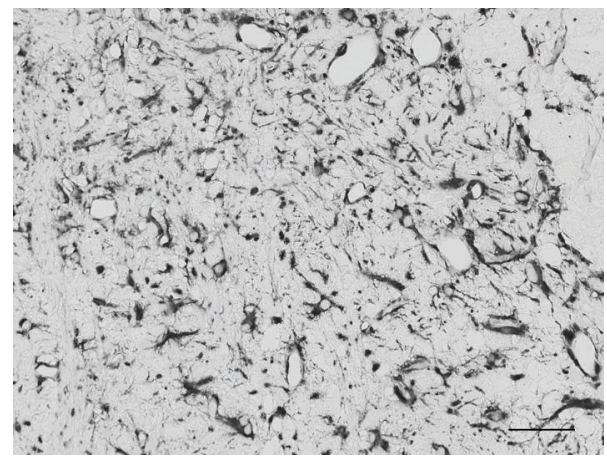

(b)

FIGURE 1: Reactive astrocytes, earmarked by enhanced expression of glial fibrillary acidic protein, hyperplasia, and gemistocytic changes, form a glial barrier in the peri-infarct area of a mouse brain at 7 days post-focal cerebral ischemia. Higher magnification image (b) represents the inset of the lower magnification coronal brain section (a). Abbreviations used: IA: infarct area; PIA: peri-infarct area. Bars denote $500 \mu \mathrm{m}$ (a) and $50 \mu \mathrm{m}$ (b).

ischemia model and noted for the first time in 1993 that there was a significant increase in infarct area during the time interval between 6 and 72 hours after ischemia onset [76]. In 1996, Du and coworkers followed up by showing that infarction after mild transient focal cerebral ischemia could develop in a delayed fashion in the rat [82]. Using the rat permanent focal cerebral ischemia model, we have shown that after the rapid expansion phase during the first 24 hours post-insult, infarct volume continues to slowly but steadily increase until it reaches a peak at 168 hours. At this time-point, there is a significant increase in infarct volume of $\sim 41 \%$ as compared to 24 hours post-insult. Moreover, the occurrence of delayed infarct expansion is associated with astrocytic activation as well as increased abundance of S100B in the peri-infarct area [81]. Clinical research relying on magnetic resonance imaging of ischemic stroke patients has disclosed that infarct expansion occurs during two distinct phases (acute and delayed) [83-85], and the time course and magnitude of ischemic enlargement are quite comparable between patients and the rat permanent focal cerebral ischemia model [81]. The above lines of evidence reinforce the idea that delayed infarct expansion is a viable therapeutic target and may even be as important as acute infarct expansion in terms of disease progression. Moreover, the 
association among the appearance of numerous peri-infarct reactive astrocytes, increased abundance of S100B in the periinfarct area, and occurrence of delayed infarct expansion has emerged as an issue of high clinical importance.

Based on the work discussed above, we undertook a series of experiments to investigate the putative causal relationship between $\mathrm{S} 100 \mathrm{~B}$ and exacerbation of brain damage. Specifically, we forced expression of human S100B or pharmacologically blocked S100B biosynthesis in rodents subjected to ischemic brain injury. We discuss our relevant findings to follow.

\subsection{Human S100B Exacerbates Ischemic Brain Damage and} Peri-Infarct Gliosis. We sought to evaluate whether forced expression of human S100B in astrocytes may exacerbate brain damage and delayed infarct expansion after permanent focal cerebral ischemia. As a corollary, we aimed to examine whether severity of delayed infarct expansion and periinfarct gliosis were correlated. To experimentally probe these questions, we utilized transgenic mice overexpressing human S100B (Tg huS100B mice; carrying approximately 10 copies of the human $\mathrm{S} 100 \mathrm{~B}$ gene under endogenous regulatory control) on an outbred CD-1 genetic background. These transgenic mice overexpress S100B in cortical astrocytes by 4-6-fold over endogenous wild-type levels [86]. We permanently induced focal cerebral ischemia by tandem occlusion of the left common carotid artery and distal segment of the middle cerebral artery using an electrocoagulation method under normothermia [87]. Notable results of this experiment are that $\mathrm{Tg}$ huS100B versus control CD-1 mice show significant exacerbation of infarct volume, neurological deficits, and peri-infarct-reactive gliosis (astrocytosis and microgliois) during the time interval between 1 and 7 days after the onset of ischemia, providing evidence for increased susceptibility of $\mathrm{Tg}$ huS100B mice to ischemic brain stress. Moreover, reactive gliosis as indicated by increased S100, GFAP, and Ibal immunoreactivity in the peri-infarct area continued to increase in Tg huS100B mice through to 7 days after focal cerebral ischemia, whereas control mice reach a plateau at 3 days following ischemic insult.

Our interpretation of the above evidence is that proinflammatory events associated with S100B-accelerated glial activation in the peri-infarct area contribute to exacerbation of brain damage. In further support of this conclusion, we noted a positive correlation between reactive gliosis along the infarct border and occurrence of delayed infarct expansion in Tg huS100B mice, but no significant relationship between these variables was detected in control animals. Together, these results support the notion that enhanced and prolonged activation of glial cells plays a detrimental role during the subacute phase ( 1 to 7 days) of focal cerebral ischemia in the rodent brain $[81,87,88]$. Moreover, our results also bolster the hypothesis that astrocyte-derived S100B is a pivotal mediator of these deleterious effects [8890]. In addition, we found that $\mathrm{Tg}$ huS100B mice had higher constitutive levels of S100 as compared with CD-1 mice. The distinction between constitutive and ischemic brain injury-enhanced S100 is important. This is because increased baseline S100 abundance may predispose to worse acute infarct expansion within 1 day after ischemic induction, whereas further induction of S100 expression likely promotes exacerbation of delayed infarct expansion.

As mentioned above, astrocytes and astrocyte-derived S100B seem to play dichotomous roles in progression of various CNS pathologies, although it is still controversial whether, on average, detrimental effects outweigh neuroprotective effects or vice versa. Since S100B can be trophic to glia [91], this effect may mechanistically underlie hyperplasia of peri-infarct reactive glia after focal cerebral ischemia in $\mathrm{Tg}$ huS100B mouse brains. Interestingly, aged rats show accelerated glial reactivity after cerebral ischemia, which coincides with impaired functional recovery [92]. Thus, worsening of neurological deficit in Tg huS100B mice after focal cerebral ischemia may be caused by inappropriately accelerated "trophic" glial responses.

The above studies adopted a genetic approach to demonstrate in vivo evidence that forced expression of human S100B exacerbates brain damage, neurological deficits, and peri-infarct reactive gliosis after ischemic stress. However, whether S100B sits at the epicenter of the damaging cytokine cycle and delayed infarct expansion needed further verification. To definitively validate this hypothesis, we examined whether pharmacological blockade of S100B biosynthesis would produce converse effects on ischemic brain damage. As detailed below, we found support that pharmacological strategies aimed at inhibiting S100B abundance would, in principle, be beneficial to mitigate cerebral ischemia.

\subsection{Suppressing S100B Synthesis Mitigates Cerebral Ischemic} Brain Damage. To examine if enhanced synthesis of S100B by peri-infarct reactive astroglia played a role in delayed infarct expansion, we undertook a pharmacological approach using a novel agent, arundic acid [ONO-2506, (R)(-)-2-propyloctanoic acid, ONO Pharmaceutical Co. Ltd.], which has been shown to suppress astrocytic S100B synthesis [93]. Yet, arundic acid exerts additional effects both in vitro and in vivo on other biomolecules, including inhibition of nerve growth factor- $\beta$, inducible nitric oxide synthase, and COX-2 expression and increasing glutathione synthesis, mRNA expression of glutamate transporters (glutamate transporter subtype 1: GLT-1 and glutamate/aspartate transporter: GLAST) and GABA receptors $\left(\mathrm{GABA}_{\mathrm{A}}-\mathrm{R} \beta 1\right.$, $\mathrm{GABA}_{A}-\mathrm{R} \beta 2$, and $\mathrm{GABA}_{A}-\mathrm{R} \beta 3$ ) in activated astrocytes. Yet, it is still unclear whether the agent modulates these other proteins directly or indirectly via its suppressive effect on S100B [93]. To model ischemic brain injury in the rat, we permanently occluded the left middle cerebral artery under normothermia and then divided at a site proximal to the origin of the lenticulostriate arteries [81]. Intravenous administration of arundic acid $(10 \mathrm{mg} / \mathrm{kg}$, once a day), initiated immediately after induction of ischemia, significantly reduced infarct volume at 168 hours (but not at 72 hours) in this rat focal cerebral ischemia model. Surprisingly, the agent did not inhibit acute infarct expansion during the initial 24 hours, but almost completely inhibited delayed infarct expansion.

In a subsequent experiment designed to elucidate a therapeutic window, rats were allocated to groups that 
received the first administration of drug at 24,48 , or 72 hours after focal cerebral ischemia, and infarct volumes were compared at 168 hours. Treatment with arundic acid commenced at 24 or 48 hours after the induction of ischemia significantly decreased infarct volumes at 168 hours by approximately $43 \%$ and $35 \%$, respectively. However, when treatment was initiated later on at 72 hours, we did not observe a protective effect. Collectively, these results show an encouraging liberal therapeutic window, which coincides with the peak of astrocytic S100B synthesis induction after focal cerebral ischemia. Numbers of apoptotic cells in the ischemic hemisphere at 72 hours post-focal cerebral ischemia were markedly decreased by arundic acid treatment. In addition, tissue levels of S100B as well as GFAP in the periinfarct area were significantly decreased by the agent. Thus, administration of arundic acid led to significant attenuation of astrocytic S100B synthesis, general inhibition of astrocytic activation, and reduced numbers of apoptotic cells in the peri-infarct area. Notably, delayed infarct expansion was almost completely inhibited in this experimental disease model. In addition, we found significant improvement in neurological scores and spontaneous activities as early as one day after the first drug treatment, and these beneficial outcomes continued for several days after treatment. These results support the concept that pharmacological inhibition of astrocytic S100B limits occurrence of delayed infarct expansion after focal cerebral ischemia.

As arundic acid does not significantly inhibit infarct expansion in the rat focal cerebral ischemia model when given beyond the 72-hour time-point, the above results indicate that the compound acts to improve later brain dysfunction through a mechanism that is temporally unrelated to inhibition of subacute infarct expansion. In this regard, it has been reported that transient focal cerebral ischemia is accompanied by relatively widespread and persistent functional disturbances in the peri-infarct region [94, 95]. Thus, improvement in neurological deficit observed after the subacute phase is likely ascribable to the beneficial actions of arundic acid on functional disturbances in the ischemic hemisphere as well as on neural plasticity in both ischemic and non-ischemic hemispheres. That neural functional derangement and delayed infarct expansion can be simultaneously mitigated by arundic acid raises the possibility that both pathologies stem from a common pathogenic mechanism: astrocytic activation. With regard to the relationship between these pathologies, it has been reported that symptoms can regress despite increase in infarct volume [25]. Results of this experiment extend the notion that pharmacological modulation of astrocytic activation via inhibiting S100B biosynthesis can have longlasting effects on functional recovery after injury, despite only reducing infarct expansion during the initial subacute phase.

The above lines of evidence from (1) a genetic model of forced human S100B expression and (2) pharmacological blockade of S100B biosynthesis bolster a causal relationship between S100B and exacerbation of ischemic brain damage. After cerebral ischemia, astrocytes change in shape and function within a relatively short time-frame, and likely exert their effects at multiple levels and at different phases of infarct evolution. During the subacute phase of focal cerebral ischemia, reactive astrocytes seem to promote delayed infarct expansion by enhancing the viscous cytokine cycle in collaboration with activated microglia. The work detailed above reinforces the idea that astrocytic synthesis of S100B plays a central role in the pathobiology of this disease, and prompts a mechanistic model wherein activated astrocytes, activated microglia, and S100B participate in brain damage and delayed infarct expansion after focal cerebral ischemia (Figure 2). A similar pathogenic mechanism seems to exist during the course of chronic neurodegeneration after focal cerebral ischemia in remote areas such as the thalamus, striatum, and substantia nigra. Since augmented astrocytic S100B synthesis accompanies a diverse number of brain pathologies, we moved on to consider the role(s) of this enigmatic molecule in neurodegenerative disease. In particular, we focused on of the relationship between S100B and $\mathrm{AD}$ pathology, as detailed to follow.

\section{Alzheimer's Disease, Neuroinflammation, and S100B}

$\mathrm{AD}$ is the most common progressive dementia of aging and is characterized by memory loss and gradual decline in cognition. AD neuropathological hallmarks include brain deposition of amyloid- $\beta$ ( $\mathrm{A} \beta)$ peptide as senile plaques, accumulation of abnormal tau protein filaments as intracellular neurofibrillary tangles, extensive neuronal degeneration and loss, profound synaptic loss, and $\beta$-amyloid plaqueassociated astrocytosis and microgliosis [96-98]. Moreover, augmented expression of $\mathrm{S} 100 \mathrm{~B}$ has been reported in the brains of patients with Down's syndrome and in $\mathrm{AD}$ [99]. In $\mathrm{AD}$, it has been shown that $\mathrm{S100B}$ abundance is elevated in activated astrocytes colocalized with $\beta$-amyloid plaques, where progressive expression of IL- $1 \alpha$ by activated microglia has also been noted [100]. Importantly, it has been reported that astroglial overexpression of S100B actually precedes appearance of neuritic $\beta$-amyloid plaques in the PDAPP mouse model of AD [101], suggesting that S100B overabundance may drive cerebral $\beta$-amyloidosis as opposed to existing as an epiphenomenon.

Brain $\mathrm{A} \beta$ deposition "normally" occurs during the course of senile changes [102], and it is probably a combination of increased accumulation/reduced clearance of the peptide and impaired ability to cope with toxic downstream effects of $\mathrm{A} \beta$ that drive $\mathrm{AD} . \mathrm{A} \beta$ is produced from sequential endoproteolytic cleavage of the type 1 transmembrane glycoprotein, $\beta$-amyloid precursor protein (APP), by $\beta$ - and $\gamma$-secretases [103-106]. Recently, it has been hypothesized that newly produced $\mathrm{A} \beta$ enters a dynamic equilibrium between soluble and deposited forms in the brain, with continual transport of soluble $\mathrm{A} \beta$ out of the brain and into the circulation [107]. In fact, cerebral amyloidosis in $\mathrm{AD}$ patient brains might be licensed by an imbalance in this dynamic equilibrium.

Rooted in the "amyloid cascade hypothesis" of $\mathrm{AD}$, which purports that accumulation of cerebral $\mathrm{A} \beta$ sets into motion a series of toxic downstream events [108, 109], extensive research efforts have been directed toward 


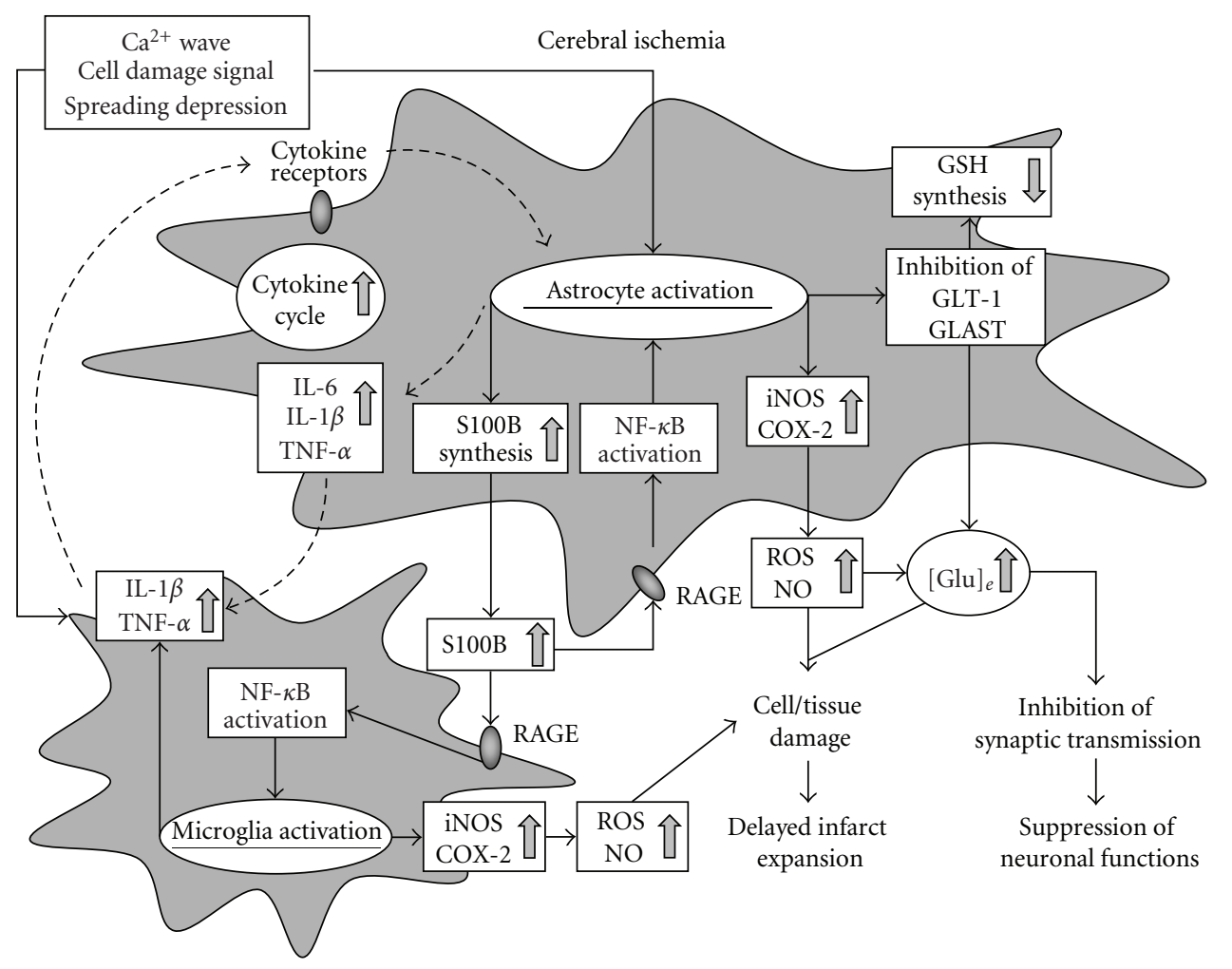

FIGURE 2: A model for the roles of activated astrocytes, activated microglia, and S100B in delayed infarct expansion after focal cerebral ischemia. The glial cytokine cycle is represented by dotted lines. Abbreviations used: COX-2: cyclooxygenase-2; [Glu $]_{\mathrm{e}}$ : extracellular glutamate; GLAST: glutamate/aspartate transporter; GLT-1: glutamate transporter subtype 1; GSH: glutathione; IL-1 $\beta$ : interleukin-1 $\beta$; IL-6: interleukin-6; iNOS: inducible nitric oxide synthase; NF- $\kappa \mathrm{B}$ : nuclear factor- $\kappa \mathrm{B}$; NO: nitric oxide; TNF- $\alpha$ : tumor necrosis factor- $\alpha$; RAGE: receptor for advanced glycation endproducts; ROS: reactive oxygen species.

development of anti-amyloid therapies aimed at reducing cerebral $\mathrm{A} \beta$ production (e.g., $\beta$ - or $\gamma$-secretase inhibitors) [110-113] or enhancing $A \beta$ clearance by targeting brain immune/inflammatory mechanisms $[27,28,114-123]$. Unfortunately, however, agents that demonstrated benefit in rodent models of $\mathrm{AD}$ have not yet lived up to their promise in the clinic, where cholinesterase inhibitors (e.g., donepezil, rivastigmine, tacrine, and galantamine) and $\mathrm{N}$ methyl D-aspartate antagonist (e.g., memantine) continue to be prescribed. It should be noted, however, that these currently indicated drugs produce only modest symptomatic benefit, especially when administered in the advanced stage of the disease. Thus, research into new drugs based on alternative therapeutic targets has continued at a feverish pace.

Over the past decade, we and others have proposed that inflammatory and immune response pathways are chronically activated in AD patient brains at low levels, and likely play a role in disease progression. "Inflammation" is canonically defined as edema and tissue infiltration of neutrophils, lymphocytes, plasma cells, and macrophages, but these classical pathological findings are not present in the post-mortem $\mathrm{AD}$ brain. Yet, accumulating evidence indicates that a variety of factors known to be major participants in inflammatory and immune responses are the norm in AD. Chronic activation of glial cells in and around $\beta$ - amyloid plaques may be pathoetiologic in $\mathrm{AD}$ via production of numerous neurotoxic acute-phase reactants, proinflammatory cytokines, and immunostimulatory molecules $[24,28,124,125]$. However, despite low-level, chronic activation of innate immunity and inflammatory responses in the $\mathrm{AD}$ brain, glial cells ultimately fail to clear cerebral $\beta$ amyloid plaques.

Astrocytes and microglia are the main innate immune response effectors in the CNS. Imbalances between protective and destructive functions of these cells might impact neurotoxicity and/or synaptotoxicity in the context of neurodegenerative disease. In the $\mathrm{AD}$ brain, reactive astrocytes and microglia co-exist in both temporal and spatial proximity with $\beta$-amyloid plaques (Figure 3), and it is thought that diffuse $\beta$-amyloid deposits attract and activate IL- $1 \beta$-secreting microglia, which in turn activate astrocytes and promote astrocyte-derived S100B synthesis. This self-propagating neuroinflammatory loop promotes further release of proinflammatory cytokines and acute-phase reactants by both activated microglia and astrocytes, leading to production of oxyradicals and nitric oxide, which are toxic at supraphysiologic levels. Aside from further enhancing inflammatory responses, these pro-inflammatory substances likely induce bystander neuronal injury in the $\mathrm{AD}$ brain $[24,124]$.

Given the conspicuous role of brain inflammation and activated astrocytes in $\mathrm{AD}$ pathobiology, we undertook 


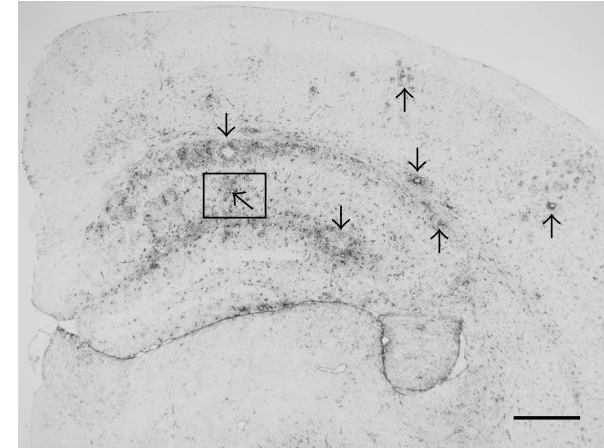

(a)

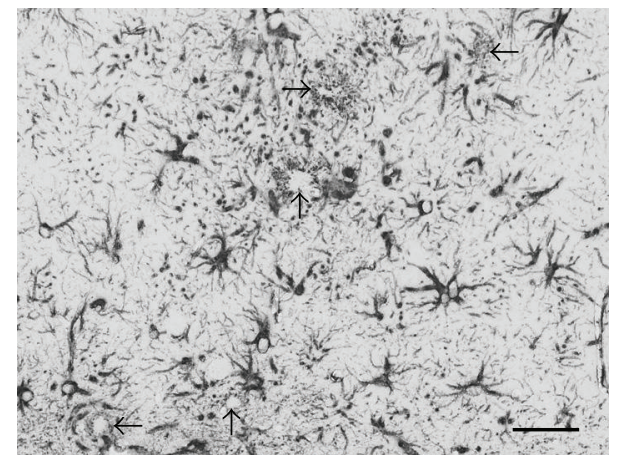

(b)

FIGURE 3: Numerous $\beta$-amyloid plaque-associated reactive astrocytes (positive for glial fibrillary acidic protein) are shown in a coronal brain section from a Tg2576 Alzheimer's disease model mouse at 19 months of age. Higher magnification image (b) represents the inset of the lower magnification coronal brain section (a). Arrows show $\beta$-amyloid plaques that are surrounded by glial fibrillary acidic protein-positive processes in the plaque periphery. Bars denote $500 \mu \mathrm{m}$ (a) and $50 \mu \mathrm{m}$ (b).

genetic and pharmacological approaches to target S100B in order to explore a putative causal relationship between S100B and progression of AD-like pathology. Our relevant findings are reviewed and discussed in the following sections.

4.1. Overexpression of Human S100B Exacerbates Alzheimer's Disease-Like Pathology. Over the past decade, numerous transgenic mouse models have been constructed using mutations in human APP and/or presenilin-1 that cause autosomal dominant early-onset AD [126]. To date, at least five lines that bear mutant human APP genes, that is, Tg2576, PDAPP, APP23, TgCRND8, and J20, have been reported and are widely used. These transgenic mouse lines differ in terms of genetic characteristics (e.g., different mutations, promoters, and/or genetic backgrounds), yielding different transgene expression levels and varying severity of $\mathrm{AD}$ like pathology. Given its wide usage as a mouse model of AD-like pathology, we adopted $\operatorname{Tg} 2576$ mice originally developed by Karen Hsiao and colleagues in the mid-90s [127]. This mouse line overproduces human $\mathrm{A} \beta_{1-40}$ and $\mathrm{A} \beta_{1-42}$ and develops progressive $\beta$-amyloid deposits and learning and memory impairment beginning at 9-10 months of age [127-129]. To examine a possible role of S100B in the progression of $\mathrm{AD}$-like pathology, we undertook a genetic approach to overproduce $\mathrm{S} 100 \mathrm{~B}$ by crossing transgenic mice expressing human S100B (TghuS100B mice) [86] with Tg2576 animals [127] to yield four genotypes of littermates: Tg2576, Tg2576-huS100B, TghuS100B, and wild-type. We then examined AD-like pathology in aged animals, including brain parenchymal and cerebral vascular $\beta$-amyloid deposits, A $\beta$ levels, $\beta$-amyloid deposit-associated gliosis (astrocytosis and microgliosis), and pro-inflammatory cytokines.

We initially noted that the huS100B transgene exacerbated age-dependent cerebral amyloidosis, including brain parenchymal and cerebral vascular $\beta$-amyloid deposits in bitransgenic mice. We also undertook a biochemical approach to measure different forms of $\mathrm{A} \beta$ peptides. Consistent with histological results, we noted elevated soluble and insoluble $\mathrm{A} \beta_{1-40}$ and $\mathrm{A} \beta_{1-42}$ abundance. In brain areas examined early on during the course of $\mathrm{A} \beta$ deposition (at 9 months of age), we observed that $\operatorname{Tg} 2576$ mice had mainly dot-like $\beta$-amyloid deposits $(<5 \mu \mathrm{m}$ in maximum diameter); by contrast, Tg2576-huS100B mice had largesized $\beta$-amyloid plaques ( $>50 \mu \mathrm{m}$ in maximum diameter) that were already present at this early age. In addition, as we did not observe $\beta$-amyloid deposits in Tg2576 or Tg2576huS100B mice at an even earlier age ( 7 months), the main difference between bigenic and singly-transgenic Tg2576 mice is higher plaque burden in the former, but not that amyloid deposition is initiated earlier in Tg2576-huS100B mice. Our findings can thus be interpreted as accelerated AD-like pathology by up to 4 months of age in TghuS100BTg2576 versus Tg2576 mice.

We also noted augmented astrocytosis and microgliosis, elevated levels of endogenous mouse S100 expression, and increased levels of pro-inflammatory cytokines (TNF- $\alpha$ and IL-1 $\beta$ ) as early as 7-9 months of age in bigenic animalsprior to the onset of frank cerebral amyloid deposits in Tg2576 mice. Others have reported that gliosis is consequent upon progressive cerebral amyloid burden in $\mathrm{AD}$ model mice, given that glial activation is proportional to $\beta$-amyloid plaque load [130-132]. However, our finding that gliosis precedes increased $\beta$-amyloid plaque deposition in Tg2576huS100B mice instead suggests that S100B-induced glial inflammatory responses drive accelerated $\beta$-amyloid load in these animals. This conclusion is strengthened by our findings that Tg2576-huS100B mice have significantly enhanced astrocytosis and microgliosis as compared to Tg2576 animals, both during initiation of cerebral amyloidosis (at 9 months of age) and at an age prior to $\beta$-amyloid deposition (at 7 months of age). However, it should be noted that we also measured pro-inflammatory cytokine mRNAs including TNF- $\alpha$, IL- $1 \beta$, IL-6, and mouse S100B at 7 months of age, and were not able to detect any consistent differences in these cytokines between the four groups of littermates. Thus, while the huS100B and Tg2576 transgenes synergize on increasing glial surface activation markers prior to formation of $\beta$ amyloid plaques (i.e., at 7 months of age), these two transgenes do not seem to cooperatively affect expression of proinflammatory cytokines until 9 months of age in this model.

The role of inflammatory responses and glial activation in the $\mathrm{AD}$ pathological process is multifarious, and studies 


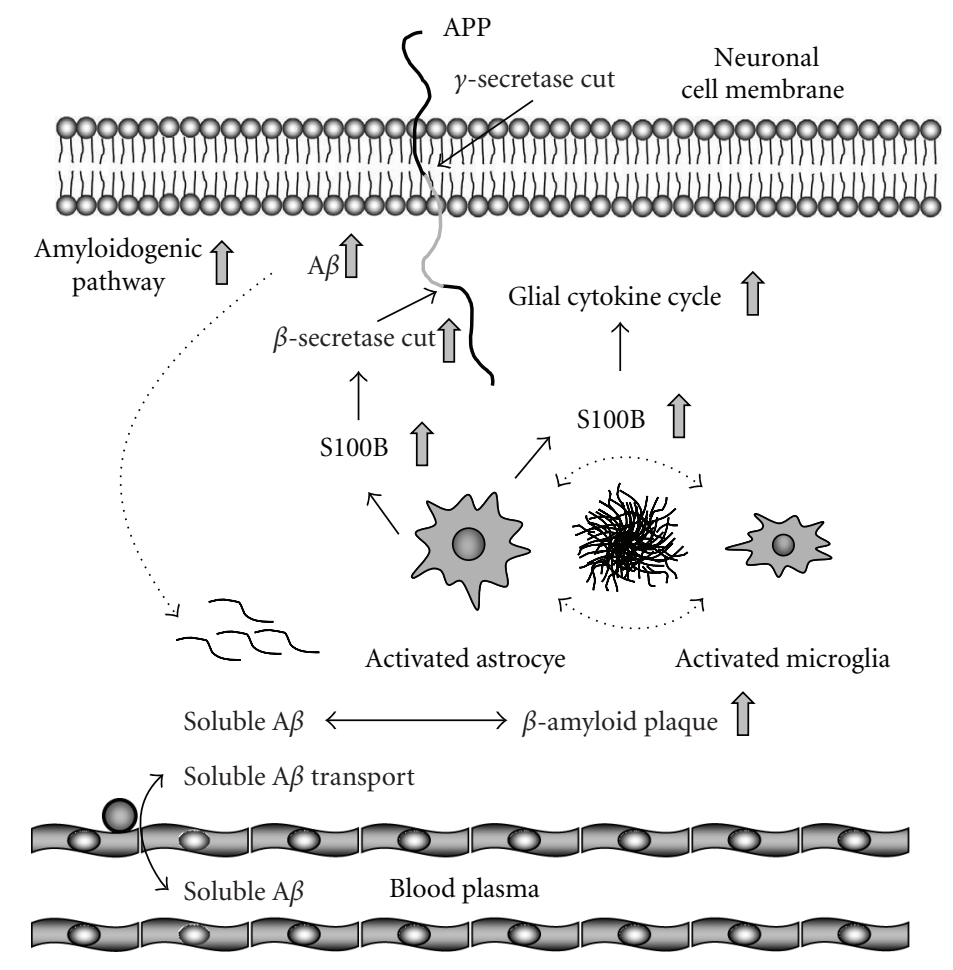

FIGURE 4: Diagrammatic representation of brain amyloid- $\beta(\mathrm{A} \beta)$ production/clearance, the harmful actions of S100B on $\mathrm{A} \beta$ production, and resultant effects on brain and plasma $\mathrm{A} \beta$ levels. In the amyloidogenic pathway, $\mathrm{A} \beta$ is primarily produced in neurons from sequential endoproteolytic cleavage of the type 1 transmembrane glycoprotein, $\beta$-amyloid precursor protein (APP), by $\beta$ - and $\gamma$-secretases. Subsequently, soluble $\mathrm{A} \beta$ is secreted into the extracellular space, and then enters into a dynamic equilibrium between soluble and deposited (insoluble, $\beta$-amyloid plaque) forms. Continual transport of soluble $\mathrm{A} \beta$ occurs into and from the plasma. S100B enhancement of $\beta$-secretase activity promotes $\mathrm{A} \beta$ production, resulting in higher soluble and deposited $\mathrm{A} \beta$ in the brain. In addition, S100B promotes a damaging glial cytokine cycle through activation of astrocytes and microglia, resulting in enhancement of the amyloidogenic pathway.

have shown both beneficial and harmful effects of glial activation on $\mathrm{AD}$-like pathology in mouse models depending on the stimulus $[90,114-117,122,132]$. These results have led to the conclusion that there are various forms of gliosis in the context of $\mathrm{AD}$, and not all forms of glial activation are damaging-some are likely even therapeutically advantageous $[26,123,133]$. The lines of evidence presented above suggest that brain pro-inflammatory events associated with S100B-dependent glial activation in close proximity to $\beta$-amyloid plaques lead to exacerbation of $\mathrm{AD}$-like pathology, supporting the notion that chronic and prolonged activation of glia is detrimental in the context of neurodegenerative disease $[81,87,134]$. Such findings lend further support to the hypothesis that the astrocyte-derived protein, S100B, exacerbates the pro-inflammatory cytokine cycle, AD-like pathology, and associated brain injury [8890]. A model depicting brain $A \beta$ production/clearance, the harmful actions of $\mathrm{S100B}$ on $\mathrm{A} \beta$ production, and resultant effects on brain and plasma $\mathrm{A} \beta$ levels is shown in Figure 4 .

Astrocyte-derived S100B promotes neurite extension and contributes to synaptogenesis and synapse remodeling in the developing and in the mature brain under physiological conditions [31, 32, 34, 38]. However, in the context of brain pathology such as $\mathrm{AD}, \mathrm{S100B}$ may confer maladaptive neuritic changes in $\beta$-amyloid plaques. Supporting this notion, it has been reported that astrocytic overexpression of S100B drives dystrophic neurite outgrowth, culminating in the formation of neuritic plaques in Down's syndrome [135], and that S100B induction precedes appearance of neuritic $\beta$-amyloid plaques in the PSAPP AD mouse model [101]. Thus, S100B may drive conversion of diffuse, nonfibrillar $\beta$-amyloid deposits to neuritic $\beta$-amyloid plaques [30]. It is noteworthy that, while $\beta$-amyloid plaque morphometric analysis disclosed significant increases in small, medium, and large plaque size subsets in Tg2576-huS100B mice, we consistently noted the greatest exacerbation in medium- and largesized plaques. Further, the huS100B transgene produced a number of "gigantic" $\beta$-amyloid plaques $(>150 \mu \mathrm{m})$ in aged bigenic mice. These data can be interpreted as consistent with a role for S100B in the maturation of $\beta$-amyloid deposits.

In addition to affecting cerebral parenchymal $\mathrm{A} \beta$ burden, the huS100B transgene also promotes cerebral vascular $\beta$ amyloid deposits. While $A \beta$ synthesis has classically been regarded to predominantly take place at neuronal synapses, it has recently been reported that reactive astrocytes surrounding $\beta$-amyloid plaques express $\beta$-secretase in $\mathrm{AD}$ patients and in Tg2576 mice $[136,137]$. Thus, the huS100B transgene may directly impact astrocytic amyloidogenic APP metabolism. This would explain both the exacerbation of parenchymal and cerebrovascular $A \beta$ deposits in bigenic 
mice. But, does S100B accelerate cerebral amyloidosis by directly promoting amyloidogenic metabolism of APP? To evaluate this possibility, we examined amyloidogenic $\beta$ carboxyl terminal fragment ( $\beta$-CTF; also known as C99) and amino-terminal APP cleavage products (soluble APP $\beta$ ) and noted increases in both species in Tg2576-huS100B versus Tg2576 mice. We also found increased levels of $\beta$ site APP cleaving enzyme 1 (BACE1; commonly known as $\beta$-secretase), and enhanced enzymatic activity in brain homogenates from Tg2576-huS100B mice. Thus, in addition to its ability to promote brain inflammatory responses, our data show that $\mathrm{S} 100 \mathrm{~B}$ has a previously unappreciated role in directly promoting amyloidogenic APP processing.

The results discussed above using an in vivo genetic approach can be interpreted as definitive evidence that forced expression of human S100B exacerbates ADlike pathology, including brain parenchymal and cerebral vascular $\beta$-amyloid deposits, $\mathrm{A} \beta$ levels, $\beta$-amyloid deposit-associated astrocytosis and microgliosis, and proinflammatory cytokines [138]. These data suggest that inhibition of S100B represents a novel therapeutic target for $\mathrm{AD}$. To further explore this tantalizing possibility, we took a pharmacological approach to blocking S100B biosynthesis, as detailed below.

\subsection{Arundic Acid Ameliorates Cerebral Amyloidosis and Gliosis} in Alzheimer Transgenic Mice. We have previously shown that arundic acid negatively regulates S100B synthesis by suppressing mRNA expression in activated astrocytes [93]. In addition, arundic acid exerts further effects both in vitro and in vivo on other biomolecules as described above. To examine whether inhibiting reactive astrocyte-derived S100B might impact progression of AD-like pathology in the Tg2576 AD mouse model [127], we orally administered the S100B biosynthesis blocker, arundic acid, to Tg2576 mice for 6 months, commencing at 12 months of age (when $\beta$-amyloid plaques are initially present in this $\mathrm{AD}$ mouse model). Strikingly, arundic acid significantly suppressed cerebral amyloidosis in treated Tg2576 mice. Importantly, $\beta$-amyloid deposits were significantly decreased in arundic acid-treated Tg2576 mice, irrespective of size. Concurrent reductions in brain levels of both soluble and insoluble $\mathrm{A} \beta$ species corroborated our histopathological observations. Notably, $\beta$-amyloid plaque-associated reactive astrocytosis and microgliosis were also significantly inhibited, suggesting that arundic acid treatment arrested the feed-forward proinflammatory cytokine cycle that would be expected to enable astrocytic activation of microglia.

In terms of a direct mechanism for the beneficial effects of arundic acid on reducing AD-like pathology, a number of possibilities deserve consideration. Firstly, the drug might alter APP expression in Tg2576 mice, either by affecting endogenous murine APP levels or by modulating the hamster prion promoter-driven mutant human APP transgene [127]. Yet, APP expression in brain homogenates was comparable between arundic acid-treated and vehicletreated Tg2576 mice, making this explanation seem unlikely. Secondly, as long-term administration of indomethacin, a key inhibitor of the inflammatory mediator NF- $\kappa \mathrm{B}$, significantly reduces cerebral amyloidosis in $\operatorname{Tg} 2576$ mice [139], and NF- $\kappa \mathrm{B}$ is downstream of S100B [58], it is possible that arundic acid-induced inhibition of NF- $\kappa \mathrm{B}$ activity may mitigate amyloidosis in Tg2576 mice. In fact, we previously observed that lipopolysaccharide-induced activation of NF- $\kappa \mathrm{B}$ in cultured astrocytes was significantly attenuated by arundic acid [93]. Thus, it seems likely that $\mathrm{NF}-\kappa \mathrm{B}$ inhibition is at least partly responsible for arundic acid-induced reduction of $A \beta$ pathology in this scenario. Thirdly, biochemical evidence of decreased brain levels of soluble and insoluble $A \beta$-against a backdrop of unaltered APP production - suggests inhibition of amyloidogenic APP metabolism in arundic acid-treated Tg2576 mice. Whether this effect occurs via direct inhibition of $\beta$-secretase, or via an indirect mechanism, remains to be elucidated. Because, as mentioned above, astrocytes express $\beta$-secretase and have been directly implicated in amyloidogenic APP metabolism in the context of $\mathrm{AD}[136,137]$, a direct mechanism of action remains possible.

Lastly, in addition to the pro-inflammatory effects of astrocytic S100B, its effects on neural reparative processes might be related to $\beta$-amyloid plaque development. It has been proposed that synaptic dysfunction occurs in both the prodromal and the clinical phases of $\mathrm{AD}$ [98], and excessive neuroplastic burden has been postulated to be a prime mover in the disease process [140]. It has been reported that astrocytic filopodia in tripartite synapses sense alterations in synaptic transmission, leading to their activation [141]. Activated astrocytes contribute to both reparative and destructive actions, which are considered to be at least partially mediated by altered levels of S100B [142]. Thus, pharmacological suppression of astrocytic S100B biosynthesis by arundic acid may have dual roles in delaying disease progression: in brain regions with relatively low levels of $\mathrm{S} 100 \mathrm{~B}$, arundic acid might inhibit neurite extension in response to cerebral amyloidosis, and thereby decrease neuroplastic burden. By contrast, in brain regions where S100B is highly expressed, the agent may suppress the pro-inflammatory autotoxic loop $[24,30]$ and thereby reduce $\beta$-amyloid plaque maturation.

\section{Concluding Remarks}

In this paper, we have considered beneficial physiological functions and detrimental roles of the astrocyte-derived protein S100B in cerebral ischemia and in AD. Importantly, we propose that both of these neurological diseases share a common pathogenic mechanism-maladaptive astrocytic activation-where S100B acts as a perpetrator of neuroinflammation and neurotoxicity. Using both genetic and pharmacological approaches, we have produced evidence supporting the idea that enhanced and prolonged activation of astrocytes plays a detrimental role in the pathogenesis of cerebral ischemia and $\mathrm{AD}$, and that astroctye-derived $\mathrm{S100B}$ is at the epicenter of these damaging cellular responses. In agreement with these lines of evidence, another group has demonstrated that S100B transgenic and knockout mice show worsening and attenuation, respectively, of ischemic brain damage [143]. In terms of $\mathrm{AD}$, there is evidence that S100B transgenic mice show enhanced susceptibility to 
neuroinflammation and neuronal dysfunction induced by intracerebroventricular infusion of human $\beta$-amlyoid [144]. These and other studies unequivocally suggest that inhibiting astrocytic activation by pharmacological blockade of S100B biosynthesis may be a valuable therapeutic strategy to combat ischemic stroke and to delay onset and/or progression of AD. As with any pharmacological approach, it is important to note that there are advantages and disadvantages to modulating astrocytic activation via targeting S100B. Since available data are limited using genetic approach(es) to elucidate the possible role(s) of S100B in CNS health and disease, further studies using S100B and RAGE knockout mice, either singly or doubly-deficient for these genes, are warranted. The availability of selective S100B biosynthesis inhibitors such as arundic acid is expected to further translational research for neurological and neurodegenerative diseases, and perhaps other disorders, such as inflammatory bowl disease, which are S100B overexpresssion-related. Such future studies will go on to address the tantalizing possibility of next-generation therapeutics for ischemic stroke and AD aimed at the pleiotropic S100B pathway.

\section{Acknowledgments}

This work was supported in part by a Grant-in-Aid for Scientific Research from the Japan Society for the Promotion of Science (no.18500279 and no.22500320, to T. Mori). T. Town is supported by a National Institute of Health/National Institute on Aging "Pathway to Independence" award (no.5R00AG029726-04). T. Town is the inaugural holder of the Ben Winters Endowed Chair in Regenerative Medicine, and is the recipient of an Alzheimer's Association Zenith Fellows Award (no. ZEN-10-174663).

\section{References}

[1] N. Spassky, F. T. Merkle, N. Flames, A. D. Tramontin, J. M. García-Verdugo, and A. Alvarez-Buylla, "Adult ependymal cells are postmitotic and are derived from radial glial cells during embryogenesis," Journal of Neuroscience, vol. 25, no. 1, pp. 10-18, 2005.

[2] X. Liu, A. J. Bolteus, D. M. Balkin, O. Henschel, and A. Bordey, "GFAP-expressing cells in the postnatal subventricular zone display a unique glial phenotype intermediate between radial glia and astrocytes," Glia, vol. 54, no. 5, pp. 394-410, 2006.

[3] Y. Chen and R. A. Swanson, "Astrocytes and brain injury," Journal of Cerebral Blood Flow and Metabolism, vol. 23, no. 2, pp. 137-149, 2003.

[4] H. Kettenmann and B. R. Ransom, Eds., Neuroglia, Oxford University Press, Oxford, UK, 2nd edition, 2005.

[5] D. D. Wang and A. Bordey, "The astrocyte odyssey," Progress in Neurobiology, vol. 86, no. 4, pp. 342-367, 2008.

[6] N. J. Allen and B. A. Barres, "Neuroscience: glia-more than just brain glue," Nature, vol. 457, no. 7230, pp. 675-677, 2009.

[7] C. M. Anderson and M. Nedergaard, "Astrocyte-mediated control of cerebral microcirculation," Trends in Neurosciences, vol. 26, no. 7, pp. 340-344, 2003.
[8] R. Parri and V. Crunelli, "An astrocyte bridge from synapse to blood flow," Nature Neuroscience, vol. 6, no. 1, pp. 5-6, 2003.

[9] T. Takano, G.-F. Tian, W. Peng et al., "Astrocyte-mediated control of cerebral blood flow," Nature Neuroscience, vol. 9, no. 2, pp. 260-267, 2006.

[10] G. R. J. Gordon, H. B. Choi, R. L. Rungta, G. C. R. EllisDavies, and B. A. MacVicar, "Brain metabolism dictates the polarity of astrocyte control over arterioles," Nature, vol. 456, no. 7223, pp. 745-749, 2008.

[11] A. Araque, G. Carmignoto, and P. G. Haydon, "Dynamic signaling between astrocytes and neurons," Annual Review of Physiology, vol. 63, pp. 795-813, 2001.

[12] D. S. Auld and R. Robitaille, "Glial cells and neurotransmission: an inclusive view of synaptic function," Neuron, vol. 40, no. 2, pp. 389-400, 2003.

[13] P. G. Haydon and G. Carmignoto, "Astrocyte control of synaptic transmission and neurovascular coupling," Physiological Reviews, vol. 86, no. 3, pp. 1009-1031, 2006.

[14] D. H. Mauch, K. Nägler, S. Schumacher et al., "CNS synaptogenesis promoted by glia-derived cholesterol," Science, vol. 294, no. 5545, pp. 1354-1357, 2001.

[15] K. Nägler, D. H. Mauch, and F. W. Pfrieger, "Glia-derived signals induce synapse formation in neurons of the rat central nervous system," Journal of Physiology, vol. 533, no. 3, pp. 665-679, 2001.

[16] E. M. Ullian, S. K. Sapperstein, K. S. Christopherson, and B. A. Barres, "Control of synapse number by glia," Science, vol. 291, no. 5504, pp. 657-661, 2001.

[17] M. Slezak and F. W. Pfrieger, "New roles for astrocytes: regulation of CNS synaptogenesis," Trends in Neurosciences, vol. 26, no. 10, pp. 531-535, 2003.

[18] A. Faissner, M. Pyka, M. Geissler et al., "Contributions of astrocytes to synapse formation and maturation-potential functions of the perisynaptic extracellular matrix," Brain Research Reviews, vol. 63, no. 1-2, pp. 26-38, 2010.

[19] H. Song, C. F. Stevens, and F. H. Gage, "Astroglia induce neurogenesis from adult neural stem cells," Nature, vol. 417, no. 6884 , pp. 39-44, 2002.

[20] A. Alvarez-Buylla and D. A. Lim, "For the long run: maintaining germinal niches in the adult brain," Neuron, vol. 41, no. 5, pp. 683-686, 2004.

[21] M. Nedergaard and U. Dirnagl, "Role of glial cells in cerebral ischemia," Glia, vol. 50, no. 4, pp. 281-286, 2005.

[22] C. Mamber, J. Verhaagen, and E. M. Hol, "In vivo targeting of subventricular zone astrocytes," Progress in Neurobiology, vol. 92, no. 1, pp. 19-32, 2010.

[23] J. G. Sheng, K. Ito, R. D. Skinner et al., "In vivo and in vitro evidence supporting a role for the inflammatory cytokine interleukin-1 as a driving force in Alzheimer pathogenesis," Neurobiology of Aging, vol. 17, no. 5, pp. 761-766, 1996.

[24] W. S. T. Griffin, J. G. Sheng, M. C. Royston et al., "Glialneuronal interactions in Alzheimer's disease: the potential role of a 'cytokine cycle' in disease progression," Brain Pathology, vol. 8, no. 1, pp. 65-72, 1998.

[25] U. Dirnagl, C. Iadecola, and M. A. Moskowitz, "Pathobiology of ischaemic stroke: an integrated view," Trends in Neurosciences, vol. 22, no. 9, pp. 391-397, 1999.

[26] T. Wyss-Coray and L. Mucke, "Inflammation in neurodegenerative disease-a double-edged sword," Neuron, vol. 35, no. 3, pp. 419-432, 2002.

[27] K. Rezai-Zadeh, D. Gate, and T. Town, "CNS infiltration of peripheral immune cells: D-Day for neurodegenerative disease?" Journal of Neuroimmune Pharmacology, vol. 4, no. 4, pp. 462-475, 2009. 
[28] T. Town, "Inflammation, immunity, and Alzheimer's disease," CNS and Neurological Disorders_Drug Targets, vol. 9, no. 2, pp. 129-131, 2010.

[29] J. L. Ridet, S. K. Malhotra, A. Privat, and F. H. Gage, "Reactive astrocytes: cellular and molecular cues to biological function," Trends in Neurosciences, vol. 20, no. 12, pp. 570$577,1997$.

[30] R. E. Mrak and W. S. T. Griffin, "The role of activated astrocytes and of the neurotrophic cytokine S100B in the pathogenesis of Alzheimer's disease," Neurobiology of Aging, vol. 22, no. 6, pp. 915-922, 2001.

[31] R. Donato, "Functional roles of S100 proteins, calciumbinding proteins of the EF-hand type," Biochimica et Biophysica Acta, vol. 1450, no. 3, pp. 191-231, 1999.

[32] R. Donato, "S100: a multigenic family of calcium-modulated proteins of the EF-hand type with intracellular and extracellular functional roles," International Journal of Biochemistry and Cell Biology, vol. 33, no. 7, pp. 637-668, 2001.

[33] C. W. Heizmann, G. Fritz, and B. W. Schäfer, "S100 proteins: structure, functions and pathology," Frontiers in Bioscience, vol. 7, pp. d1356-d1368, 2002.

[34] R. Donato, "Intracellular and extracellular roles of S100 proteins," Microscopy Research and Technique, vol. 60, no. 6, pp. 540-551, 2003.

[35] I. Marenholz, C. W. Heizmann, and G. Fritz, "S100 proteins in mouse and man: from evolution to function and pathology (including an update of the nomenclature)," Biochemical and Biophysical Research Communications, vol. 322, no. 4, pp. 1111-1122, 2004.

[36] I. Marenholz, R. C. Lovering, and C. W. Heizmann, "An update of the S100 nomenclature," Biochimica et Biophysica Acta, vol. 1763, no. 11, pp. 1282-1283, 2006.

[37] L. Santamaria-Kisiel, A. C. Rintala-Dempsey, and G. S. Shaw, "Calcium-dependent and -independent interactions of the S100 protein family," Biochemical Journal, vol. 396, no. 2, pp. 201-214, 2006.

[38] R. Donato, G. Sorci, F. Riuzzi et al., "S100B's double life: intracellular regulator and extracellular signal," Biochimica et Biophysica Acta, vol. 1793, no. 6, pp. 1008-1022, 2009.

[39] D. B. Zimmer, J. Chaplin, A. Baldwin, and M. Rast, "S100mediated signal transduction in the nervous system and neurological diseases," Cellular and Molecular Biology, vol. 51, no. 2, pp. 201-214, 2005.

[40] V. Vives, G. Alonso, A. C. Solal, D. Joubert, and C. Legraverend, "Visualization of S100B-positive neurons and glia in the central nervous system of EGFP transgenic mice," Journal of Comparative Neurology, vol. 457, no. 4, pp. 404419, 2003.

[41] J. C. Deloulme, E. Raponi, B. J. Gentil et al., "Nuclear expression of S100B in oligodendrocyte progenitor cells correlates with differentiation toward the oligodendroglial lineage and modulates oligodendrocytes maturation," Molecular and Cellular Neuroscience, vol. 27, no. 4, pp. 453-465, 2004.

[42] S. Hachem, A.-S. Laurenson, J.-P. Hugnot, and C. Legraverend, "Expression of S100B during embryonic development of the mouse cerebellum," BMC Developmental Biology, vol. 7, Article ID 17, 2007.

[43] S. W. Barger and L. J. Van Eldik, "S100 $\beta$ stimulates calcium fluxes in glial and neuronal cells," Journal of Biological Chemistry, vol. 267, no. 14, pp. 9689-9694, 1992.

[44] B. W. Schäfer and C. W. Heizmann, "The S100 family of EFhand calcium-binding proteins: functions and pathology," Trends in Biochemical Sciences, vol. 21, no. 4, pp. 134-140, 1996.
[45] C. W. Heizmann and J. A. Cox, "New perspectives on S100 proteins: a multi-functional $\mathrm{Ca}^{2+}-, \mathrm{Zn}^{2+}$ - and $\mathrm{Cu}^{2+}$-binding protein family," BioMetals, vol. 11, no. 4, pp. 383-397, 1998.

[46] P. T. Wilder, J. Lin, C. L. Bair et al., "Recognition of the tumor suppressor protein p53 and other protein targets by the calcium-binding protein S100B," Biochimica et Biophysica Acta, vol. 1763, no. 11, pp. 1284-1297, 2006.

[47] J. Baudier, C. Delphin, D. Grunwald, S. Khochbin, and J. J. Lawrence, "Characterization of the tumor suppressor protein p53 as a protein kinase C substrate and a S100b-binding protein," Proceedings of the National Academy of Sciences of the United States of America, vol. 89, no. 23, pp. 11627-11631, 1992.

[48] T. M. Johnson, Z.-X. Yu, V. J. Ferrans, R. A. Lowenstein, and T. Finkel, "Reactive oxygen species are downstream mediators of p53-dependent apoptosis," Proceedings of the National Academy of Sciences of the United States of America, vol. 93, no. 21, pp. 11848-11852, 1996.

[49] C. Scotto, J. C. Deloulme, D. Rousseau, E. Chambaz, and J. Baudier, "Calcium and S100B regulation of p53-dependent cell growth arrest and apoptosis," Molecular and Cellular Biology, vol. 18, no. 7, pp. 4272-4281, 1998.

[50] F. W. Pfrieger and B. A. Barres, "New views on synapse-glia interactions," Current Opinion in Neurobiology, vol. 6, no. 5, pp. 615-621, 1996.

[51] T. J. Cicero, J. A. Ferrendelli, V. Suntzeff, and B. W. Moore, "Regional changes in CNS levels of the S-100 and 14-3-2 proteins during development and aging of the mouse," Journal of Neurochemistry, vol. 19, no. 9, pp. 2119-2125, 1972.

[52] K. G. Haglid, H. A. Hansson, and L. Rönnbäck, "S-100 in the central nervous system of rat, rabbit and guinea pig during postnatal development," Brain Research, vol. 123, no. 2, pp. 331-345, 1977.

[53] D. Kligman and D. R. Marshak, "Purification and characterization of a neurite extension factor from bovine brain," Proceedings of the National Academy of Sciences of the United States of America, vol. 82, no. 20, pp. 7136-7139, 1985.

[54] L. J. Van Eldik, B. Christie-Pope, L. M. Bolin, E. M. Shooter, and W. O. Whetsell Jr., "Neurotrophic activity of S-100 $\beta$ in cultures of dorsal root ganglia from embryonic chick and fetal rat," Brain Research, vol. 542, no. 2, pp. 280-285, 1991.

[55] S. W. Barger, L. J. Van Eldik, and M. P. Mattson, "S100 $\beta$ protects hippocampal neurons from damage induced by glucose deprivation," Brain Research, vol. 677, no. 1, pp. 167-170, 1995.

[56] B. Ahlemeyer, H. Beier, I. Semkova, C. Schaper, and J. Krieglstein, "S-100 $\beta$ protects cultured neurons against glutamate- and staurosporine-induced damage and is involved in the antiapoptotic action of the $5 \mathrm{HT}_{1 A}$-receptor agonist, Bay x 3702," Brain Research, vol. 858, no. 1, pp. 121-128, 2000.

[57] J. Hu, A. Ferreira, and L. J. Van Eldik, "S100 $\beta$ induces neuronal cell death through nitric oxide release from astrocytes," Journal of Neurochemistry, vol. 69, no. 6, pp. 2294-2301, 1997.

[58] A. G. M. Lam, T. Koppal, K. T. Akama et al., "Mechanism of glial activation by S100B: involvement of the transcription factor NFkB," Neurobiology of Aging, vol. 22, no. 5, pp. 765-772, 2001.

[59] J. Hu and L. J. Van Eldik, "Glial-derived proteins activate cultured astrocytes and enhance $\beta$ amyloid-induced glial activation," Brain Research, vol. 842, no. 1, pp. 46-54, 1999. 
[60] G. Ponath, C. Schettler, F. Kaestner et al., "Autocrine S100B effects on astrocytes are mediated via RAGE," Journal of Neuroimmunology, vol. 184, no. 1-2, pp. 214-222, 2007.

[61] M. A. Hofmann, S. Drury, C. Fu et al., "RAGE mediates a novel proinflammatory axis: a central cell surface receptor for S100/calgranulin polypeptides," Cell, vol. 97, no. 7, pp. 889-901, 1999.

[62] L. G. Bucciarelli, T. Wendt, L. Rong et al., "RAGE is a multiligand receptor of the immunoglobulin superfamily: implications for homeostasis and chronic disease," Cellular and Molecular Life Sciences, vol. 59, no. 7, pp. 1117-1128, 2002.

[63] R. Donato, "RAGE: a single receptor for several ligands and different cellular responses: the case of certain S100 proteins," Current Molecular Medicine, vol. 7, no. 8, pp. 711-724, 2007.

[64] E. Leclerc, G. Fritz, S. W. Vetter, and C. W. Heizmann, "Binding of S100 proteins to RAGE: an update," Biochimica et Biophysica Acta, vol. 1793, no. 6, pp. 993-1007, 2009.

[65] R. Bianchi, I. Giambanco, and R. Donato, "S100B/RAGEdependent activation of microglia via NF- $\kappa \mathrm{B}$ and AP-1. Coregulation of COX-2 expression by S100B, IL- $1 \beta$ and TNF- $\alpha$," Neurobiology of Aging, vol. 31, no. 4, pp. 665-677, 2010.

[66] J. Li and A. M. Schmidt, "Characterization and functional analysis of the promoter of RAGE, the receptor for advanced glycation end products," Journal of Biological Chemistry, vol. 272, no. 26, pp. 16498-16506, 1997.

[67] H. J. Huttunen, J. Kuja-Panula, G. Sorci, A. L. Agneletti, R. Donato, and H. Rauvala, "Coregulation of neurite outgrowth and cell survival by amphoterin and S100 proteins through receptor for advanced glycation end products (RAGE) activation," Journal of Biological Chemistry, vol. 275, no. 51, pp. 40096-40105, 2000.

[68] S. H. Kim, C. J. Smith, and L. J. Van Eldik, "Importance of MAPK pathways for microglial pro-inflammatory cytokine IL-1 $\beta$ production," Neurobiology of Aging, vol. 25, no. 4, pp. 431-439, 2004.

[69] G. J. del Zoppo and T. Mabuchi, "Cerebral microvessel responses to focal ischemia," Journal of Cerebral Blood Flow and Metabolism, vol. 23, no. 8, pp. 879-894, 2003.

[70] P. Sanchez-Peña, A.-R. Pereira, N.-A. Sourour et al., "S100B as an additional prognostic marker in subarachnoid aneurysmal hemorrhage," Critical Care Medicine, vol. 36, no. 8, pp. 2267-2273, 2008.

[71] S. Moritz, J. Warnat, S. Bele, B. M. Graf, and C. Woertgen, "The prognostic value of NSE and S100B from serum and cerebrospinal fluid in patients with spontaneous subarachnoid hemorrhage," Journal of Neurosurgical Anesthesiology, vol. 22, no. 1, pp. 21-31, 2010.

[72] U. Missler, M. Wiesmann, C. Friedrich, and M. Kaps, "S-100 protein and neuron-specific enolase concentrations in blood as indicators of infarction volume and prognosis in acute ischemic stroke," Stroke, vol. 28, no. 10, pp. 1956-1960, 1997.

[73] C. Foerch, B. Otto, O. C. Singer et al., "Serum S100B predicts a malignant course of infarction in patients with acute middle cerebral artery occlusion," Stroke, vol. 35, no. 9, pp. 2160-2164, 2004.

[74] O. Savola, J. Pyhtinen, T. K. Leino, S. Siitonen, O. Niemelä, and M. Hillbom, "Effects of head and extracranial injuries on serum protein S100B levels in trauma patients," Journal of Trauma, vol. 56, no. 6, pp. 1229-1234, 2004.

[75] C. K. Petito, S. Morgello, J. C. Felix, and M. L. Lesser, "The two patterns of reactive astrocytosis in postischemic rat brain," Journal of Cerebral Blood Flow and Metabolism, vol. 10, no. 6, pp. 850-859, 1990.
[76] J. H. Garcia, Y. Yoshida, H. Chen et al., "Progression from ischemic injury to infarct following middle cerebral artery occlusion in the rat," American Journal of Pathology, vol. 142, no. 2, pp. 623-635, 1993.

[77] K. Yamashita, P. Vogel, K. Fritze, T. Back, K.-A. Hossmann, and C. Wiessner, "Monitoring the temporal and spatial activation pattern of astrocytes in focal cerebral ischemia using in situ hybridization of GFAP mRNA: comparison with sgp-2 and hsp70 mRNA and the effect of glutamate receptor antagonists," Brain Research, vol. 735, no. 2, pp. 285-297, 1996.

[78] J. Silver and J. H. Miller, "Regeneration beyond the glial scar," Nature Reviews Neuroscience, vol. 5, no. 2, pp. 146-156, 2004.

[79] L. Wei, J. P. Erinjeri, C. M. Rovainen, and T. A. Woolsey, "Collateral growth and angiogenesis around cortical stroke," Stroke, vol. 32, no. 9, pp. 2179-2184, 2001.

[80] J. H. Garcia and Y. Kamijyo, "Cerebral infarction. Evolution of histopathological changes after occlusion of a middle cerebral artery in primates," Journal of Neuropathology and Experimental Neurology, vol. 33, no. 3, pp. 408-421, 1974.

[81] T. Matsui, T. Mori, N. Tateishi et al., "Astrocytic activation and delayed infarct expansion after permanent focal ischemia in rats. Part I: enhanced astrocytic synthesis of S-100 $\beta$ in the periinfarct area precedes delayed infarct expansion," Journal of Cerebral Blood Flow and Metabolism, vol. 22, no. 6, pp. 711-722, 2002.

[82] C. Du, R. Hu, C. A. Csernansky, C. Y. Hsu, and D. W. Choi, "Very delayed infarction after mild focal cerebral ischemia: a role for apoptosis?" Journal of Cerebral Blood Flow and Metabolism, vol. 16, no. 2, pp. 195-201, 1996.

[83] S. Warach, J. Gaa, B. Siewert, P. Wielopolski, and R. R. Edelman, "Acute human stroke studied by whole brain echo planar diffusion-weighted magnetic resonance imaging," Annals of Neurology, vol. 37, no. 2, pp. 231-241, 1995.

[84] A. E. Baird, A. Benfield, G. Schlaug et al., "Enlargement of human cerebral ischemic lesion volumes measured by diffusion-weighted magnetic resonance imaging," Annals of Neurology, vol. 41, no. 5, pp. 581-589, 1997.

[85] C. Beaulieu, A. de Crespigny, D. C. Tong, M. E. Moseley, G. W. Albers, and M. P. Marks, "Longitudinal magnetic resonance imaging study of perfusion and diffusion in stroke: evolution of lesion volume and correlation with clinical outcome," Annals of Neurology, vol. 46, no. 4, pp. 568-578, 1999.

[86] W. C. Friend, S. Clapoff, C. Landry et al., "Cell-specific expression of high levels of human $\mathrm{S} 100 \beta$ in transgenic mouse brain is dependent on gene dosage," Journal of Neuroscience, vol. 12, no. 11, pp. 4337-4346, 1992.

[87] T. Mori, T. Town, M. Kobayashi, J. Tan, S. C. Fujita, and T. Asano, "Augmented delayed infarct expansion and reactive astrocytosis after permanent focal ischemia in apolipoprotein E4 knock-in mice," Journal of Cerebral Blood Flow and Metabolism, vol. 24, no. 6, pp. 646-656, 2004.

[88] T. Mori, T. Town, J. Tan, N. Tateishi, and T. Asano, "Modulation of astrocytic activation by arundic acid (ONO2506) mitigates detrimental effects of the apolipoprotein E4 isoform after permanent focal ischemia in apolipoprotein E knock-in mice," Journal of Cerebral Blood Flow and Metabolism, vol. 25, no. 6, pp. 748-762, 2005.

[89] N. Tateishi, T. Mori, Y. Kagamiishi et al., "Astrocytic activation and delayed infarct expansion after permanent focal ischemia in rats. Part II: suppression of astrocytic activation by a novel agent $(R)-(-)$-2-propyloctanoic acid (ONO-2506) leads to mitigation of delayed infarct expansion and early improvement of neurologic deficits," Journal of Cerebral Blood Flow and Metabolism, vol. 22, no. 6, pp. 723-734, 2002. 
[90] T. Mori, T. Town, J. Tan et al., "Arundic acid ameliorates cerebral amyloidosis and gliosis in Alzheimer transgenic mice," Journal of Pharmacology and Experimental Therapeutics, vol. 318, no. 2, pp. 571-578, 2006.

[91] R. H. Selinfreund, S. W. Barger, W. J. Pledger, and L. J. Van Eldik, "Neurotrophic protein S100 $\beta$ stimulates glial cell proliferation," Proceedings of the National Academy of Sciences of the United States of America, vol. 88, no. 9, pp. 3554-3558, 1991.

[92] I. Badan, B. Buchhold, A. Hamm et al., "Accelerated glial reactivity to stroke in aged rats correlates with reduced functional recovery," Journal of Cerebral Blood Flow and Metabolism, vol. 23, no. 7, pp. 845-854, 2003.

[93] T. Asano, T. Mori, T. Shimoda et al., "Arundic acid (ONO2506) ameliorates delayed ischemic brain damage by preventing astrocytic overproduction of S100B," Current Drug Targets-CNS and Neurological Disorders, vol. 4, no. 2, pp. 127-142, 2005.

[94] T. Neumann-Haefelin and O. W. Witte, "Periinfarct and remote excitability changes after transient middle cerebral artery occlusion," Journal of Cerebral Blood Flow and Metabolism, vol. 20, no. 1, pp. 45-52, 2000.

[95] O. W. Witte, H.-J. Bidmon, K. Schiene, C. Redecker, and G. Hagemann, "Functional differentiation of multiple perilesional zones after focal cerebral ischemia," Journal of Cerebral Blood Flow and Metabolism, vol. 20, no. 8, pp. 1149-1165, 2000.

[96] D. J. Selkoe, T. Yamazaki, M. Citron et al., "The role of APP processing and trafficking pathways in the formation of amyloid $\beta$-protein," Annals of the New York Academy of Sciences, vol. 777, pp. 57-64, 1996.

[97] D. J. Selkoe, "Alzheimer's disease: genes, proteins, and therapy," Physiological Reviews, vol. 81, no. 2, pp. 741-766, 2001.

[98] D. J. Selkoe, "Alzheimer's disease is a synaptic failure," Science, vol. 298, no. 5594, pp. 789-791, 2002.

[99] W. S. T. Griffin, L. C. Stanley, C. Ling et al., "Brain interleukin 1 and S-100 immunoreactivity are elevated in Down syndrome and Alzheimer disease," Proceedings of the National Academy of Sciences of the United States of America, vol. 86, no. 19, pp. 7611-7615, 1989.

[100] J. G. Sheng, R. E. Mrak, and W. S. T. Griffin, "Glial-neuronal interactions in Alzheimer disease: progressive association of IL- $1 \alpha+$ microglia and S100 $\beta+$ astrocytes with neurofibrillary tangle stages," Journal of Neuropathology and Experimental Neurology, vol. 56, no. 3, pp. 285-290, 1997.

[101] J. G. Sheng, R. E. Mrak, K. R. Bales et al., "Overexpression of the neuritotrophic cytokine $S 100 \beta$ precedes the appearance of neuritic $\beta$-amyloid plaques in APPV717F mice," Journal of Neurochemistry, vol. 74, no. 1, pp. 295-301, 2000.

[102] L.-F. Lue, Y.-M. Kuo, A. E. Roher et al., "Soluble amyloid $\beta$ peptide concentration as a predictor of synaptic change in Alzheimer's disease," American Journal of Pathology, vol. 155, no. 3, pp. 853-862, 1999.

[103] B. De Strooper, P. Saftig, K. Craessaerts et al., "Deficiency of presenilin-1 inhibits the normal cleavage of amyloid precursor protein," Nature, vol. 391, no. 6665, pp. 387-390, 1998.

[104] S. Sinha and I. Lieberburg, "Cellular mechanisms of $\beta$ amyloid production and secretion," Proceedings of the National Academy of Sciences of the United States of America, vol. 96, no. 20, pp. 11049-11053, 1999.

[105] R. Yan, M. J. Bienkowski, M. E. Shuck et al., "Membraneanchored aspartyl protease with Alzheimer's disease $\beta$-secretase activity," Nature, vol. 402, no. 6761, pp. 533-537, 1999.
[106] J. Nunan and D. H. Small, "Regulation of APP cleavage by $\alpha$-, $\beta$ - and $\gamma$-secretases," FEBS Letters, vol. 483, no. 1, pp. 6-10, 2000.

[107] R. B. DeMattos, K. R. Bales, D. J. Cummins, S. M. Paul, and D. M. Holtzman, "Brain to plasma amyloid- $\beta$ efflux: a measure of brain amyloid burden in a mouse model of Alzheimer's disease," Science, vol. 295, no. 5563, pp. 2264-2267, 2002.

[108] J. Hardy and D. Allsop, "Amyloid deposition as the central event in the aetiology of Alzheimer's disease," Trends in Pharmacological Sciences, vol. 12, no. 10, pp. 383-388, 1991.

[109] B. A. Yankner and T. Lu, "Amyloid $\beta$-protein toxicity and the pathogenesis of Alzheimer disease," Journal of Biological Chemistry, vol. 284, no. 8, pp. 4755-4759, 2009.

[110] K. Rezai-Zadeh, D. Shytle, N. Sun et al., "Green tea epigallocatechin-3-gallate (EGCG) modulates amyloid precursor protein cleavage and reduces cerebral amyloidosis in Alzheimer transgenic mice," Journal of Neuroscience, vol. 25, no. 38, pp. 8807-8814, 2005.

[111] D. F. Obregon, K. Rezai-Zadeh, Y. Bai et al., "ADAM10 activation is required for green tea (-)-epigallocatechin-3gallate-induced $\alpha$-secretase cleavage of amyloid precursor protein," Journal of Biological Chemistry, vol. 281, no. 24, pp. 16419-16427, 2006.

[112] G. W. Arendash, T. Mori, C. Cao et al., "Caffeine reverses cognitive impairment and decreases brain amyloid- $\beta$ levels in aged Alzheimer's disease mice," Journal of Alzheimer's Disease, vol. 17, no. 3, pp. 661-680, 2009.

[113] K. Rezai-Zadeh, R. Douglas Shytle, Y. Bai et al., "Flavonoidmediated presenilin-1 phosphorylation reduces Alzheimer's disease $\beta$-amyloid production," Journal of Cellular and Molecular Medicine, vol. 13, no. 3, pp. 574-588, 2009.

[114] D. Schenk, R. Barbour, W. Dunn et al., "Immunization with amyloid- $\beta$ attenuates Alzheimer disease-like pathology in the PDAPP mouse," Nature, vol. 400, no. 6740, pp. 173-177, 1999.

[115] J. Tan, T. Town, D. Paris et al., "Microglial activation resulting from CD40-CD40L interaction after $\beta$-amyloid stimulation," Science, vol. 286, no. 5448, pp. 2352-2355, 1999.

[116] F. Bard, C. Cannon, R. Barbour et al., "Peripherally administered antibodies against amyloid $\beta$-peptide enter the central nervous system and reduce pathology in a mouse model of Alzheimer disease," Nature Medicine, vol. 6, no. 8, pp. 916-919, 2000.

[117] J. Tan, T. Town, F. Crawford et al., "Role of CD40 ligand in amyloidosis in transgenic Alzheimer's mice," Nature Neuroscience, vol. 5, no. 12, pp. 1288-1293, 2002.

[118] J. Tan, T. Town, and M. Mullan, "CD40-CD40L interaction in Alzheimer's disease," Current Opinion in Pharmacology, vol. 2, no. 4, pp. 445-451, 2002.

[119] T. Town, M. Vendrame, A. Patel et al., "Reduced Th1 and enhanced Th2 immunity after immunization with Alzheimer's $\beta$-amyloid and $_{1-4}$, Journal of Neuroimmunology, vol. 132, no. 1-2, pp. 49-59, 2002.

[120] W. V. Nikolic, Y. Bai, D. Obregon et al., “Transcutaneous $\beta$-amyloid immunization reduces cerebral $\beta$-amyloid deposits without T cell infiltration and microhemorrhage," Proceedings of the National Academy of Sciences of the United States of America, vol. 104, no. 7, pp. 2507-2512, 2007.

[121] W. V. Nikolic, H. Hou, T. Town et al., "Peripherally administered human umbilical cord blood cells reduce parenchymal and vascular $\beta$-amyloid deposits in Alzheimer mice," Stem Cells and Development, vol. 17, no. 3, pp. 423-439, 2008. 
[122] T. Town, Y. Laouar, C. Pittenger et al., "Blocking TGF- $\beta$ Smad2/3 innate immune signaling mitigates Alzheimer-like pathology," Nature Medicine, vol. 14, no. 6, pp. 681-687, 2008.

[123] T. Town, "Alternative A $\beta$ immunotherapy approaches for Alzheimer's disease," CNS and Neurological Disorders-Drug Targets, vol. 8, no. 2, pp. 114-127, 2009.

[124] H. Akiyama, S. Barger, S. Barnum et al., "Inflammation and Alzheimer's disease," Neurobiology of Aging, vol. 21, no. 3, pp. 383-421, 2000.

[125] B. Giunta, F. Fernandez, W. V. Nikolic et al., "Inflammaging as a prodrome to Alzheimer's disease," Journal of Neuroinflammation, vol. 5, Article ID 51, 2008.

[126] Y. S. Mineur, D. McLoughlin, W. E. Crusio, and F. Sluyter, "Genetic mouse models of Alzheimer's disease," Neural Plasticity, vol. 12, no. 4, pp. 299-310, 2005.

[127] K. Hsiao, P. Chapman, S. Nilsen et al., "Correlative memory deficits, $\mathrm{A} \beta$ elevation, and amyloid plaques in transgenic mice," Science, vol. 274, no. 5284, pp. 99-102, 1996.

[128] T. Kawarabayashi, L. H. Younkin, T. C. Saido, M. Shoji, K. H. Ashe, and S. G. Younkin, "Age-dependent changes in brain, CSF, and plasma amyloid $\beta$ protein in the Tg2576 transgenic mouse model of Alzheimer's disease," Journal of Neuroscience, vol. 21, no. 2, pp. 372-381, 2001.

[129] S. Lesné, M. T. Koh, L. Kotilinek et al., "A specific amyloid- $\beta$ protein assembly in the brain impairs memory," Nature, vol. 440, no. 7082, pp. 352-357, 2006.

[130] W. C. Benzing, J. R. Wujek, E. K. Ward et al., "Evidence for glial-mediated inflammation in aged $\mathrm{APP}_{\mathrm{SW}}$ transgenic mice," Neurobiology of Aging, vol. 20, no. 6, pp. 581-589, 1999.

[131] M. Stalder, A. Phinney, A. Probst, B. Sommer, M. Staufenbiel, and M. Jucker, "Association of microglia with amyloid plaques in brains of APP23 transgenic mice," American Journal of Pathology, vol. 154, no. 6, pp. 1673-1684, 1999.

[132] G. P. Lim, F. Yang, T. Chu et al., "Ibuprofen suppresses plaque pathology and inflammation in a mouse model for Alzheimer's disease," Journal of Neuroscience, vol. 20, no. 15, pp. 5709-5714, 2000.

[133] T. Town, V. Nikolic, and J. Tan, "The microglial "activation" continuum: from innate to adaptive responses," Journal of Neuroinflammation, vol. 2, Article ID 24, 2005.

[134] T. Mori, J. Tan, G. W. Arendash, N. Koyama, Y. Nojima, and T. Town, "Overexpression of human S100B exacerbates brain damage and periinfarct gliosis after permanent focal ischemia," Stroke, vol. 39, no. 7, pp. 2114-2121, 2008.

[135] W. S. T. Griffin, J. G. Sheng, J. E. McKenzie et al., "Life-long overexpression of $S 100 \beta$ in Down's syndrome: implications for Alzheimer pathogenesis," Neurobiology of Aging, vol. 19, no. 5, pp. 401-405, 1998.

[136] M. Hartlage-Rübsamen, U. Zeitschel, J. Apelt et al., "Astrocytic expression of the Alzheimer's disease $\beta$-secretase (BACE1) is stimulus-dependent," Glia, vol. 41, no. 2, pp. 169-179, 2003.

[137] M. Yamamoto, T. Kiyota, M. Horiba et al., "Interferon- $\gamma$ and tumor necrosis factor- $\alpha$ regulate amyloid- $\beta$ plaque deposition and $\beta$-secretase expression in Swedish mutant APP transgenic mice," American Journal of Pathology, vol. 170, no. 2, pp. 680-692, 2007.

[138] T. Mori, N. Koyama, G. W. Arendash, Y. HorikoshiSakuraba, J. Tan, and T. Town, "Overexpression of human $\mathrm{S} 100 \mathrm{~B}$ exacerbates cerebral amyloidosis and gliosis in the Tg2576 mouse model of Alzheimer's disease," Glia, vol. 58, no. 3, pp. 300-314, 2010.
[139] S. Sung, H. Yang, K. Uryu et al., "Modulation of nuclear factor- $\kappa \mathrm{B}$ activity by indomethacin influences $\mathrm{A} \beta$ levels but not $\mathrm{A} \beta$ precursor protein metabolism in a model of Alzheimer's disease," American Journal of Pathology, vol. 165, no. 6, pp. 2197-2206, 2004.

[140] M.-M. Mesulam, "Neuroplasticity failure in Alzheimer's disease: bridging the gap between plaques and tangles," Neuron, vol. 24, no. 3, pp. 521-529, 1999.

[141] P. G. Haydon, "Glia: listening and talking to the synapse," Nature Reviews Neuroscience, vol. 2, no. 3, pp. 185-193, 2001.

[142] B. S. McAdory, L. J. Van Eldik, and J. J. Norden, "S100B, a neurotropic protein that modulates neuronal protein phosphorylation, is upregulated during lesion-induced collateral sprouting and reactive synaptogenesis," Brain Research, vol. 813, no. 1, pp. 211-217, 1998.

[143] M. S. Wainwright, J. M. Craft, W. S. T. Griffin et al., "Increased susceptibility of S100B transgenic mice to perinatal hypoxia-ischemia," Annals of Neurology, vol. 56, no. 1, pp. 61-67, 2004.

[144] J. M. Craft, D. M. Watterson, A. Marks, and L. J. Van Eldik, "Enhanced susceptibility of S-100B transgenic mice to neuroinflammation and neuronal dysfunction induced by intracerebroventricular infusion of human $\beta$-amyloid," Glia, vol. 51, no. 3, pp. 209-216, 2005. 


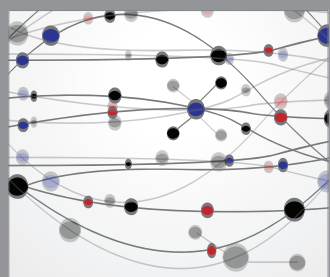

The Scientific World Journal
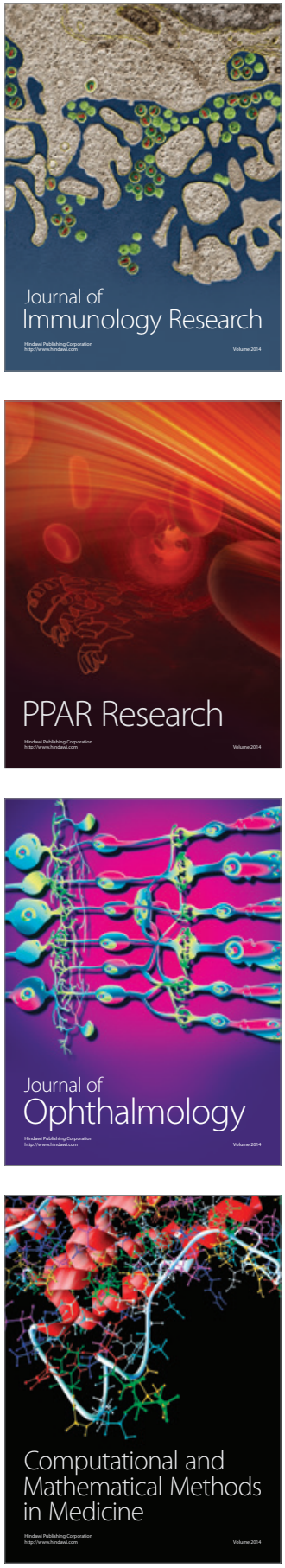

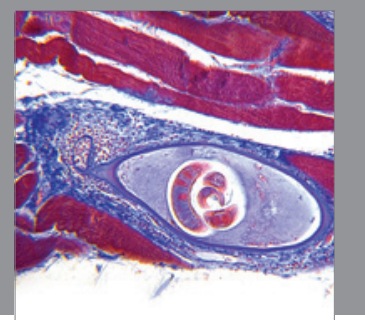

Gastroenterology

Research and Practice
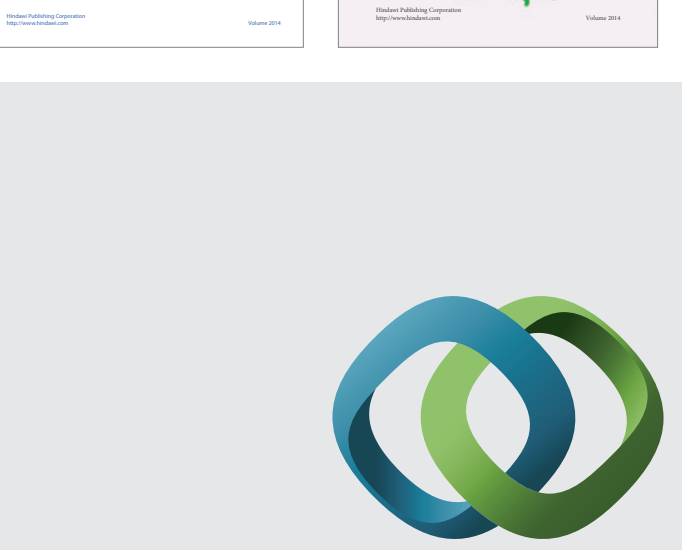

\section{Hindawi}

Submit your manuscripts at

http://www.hindawi.com
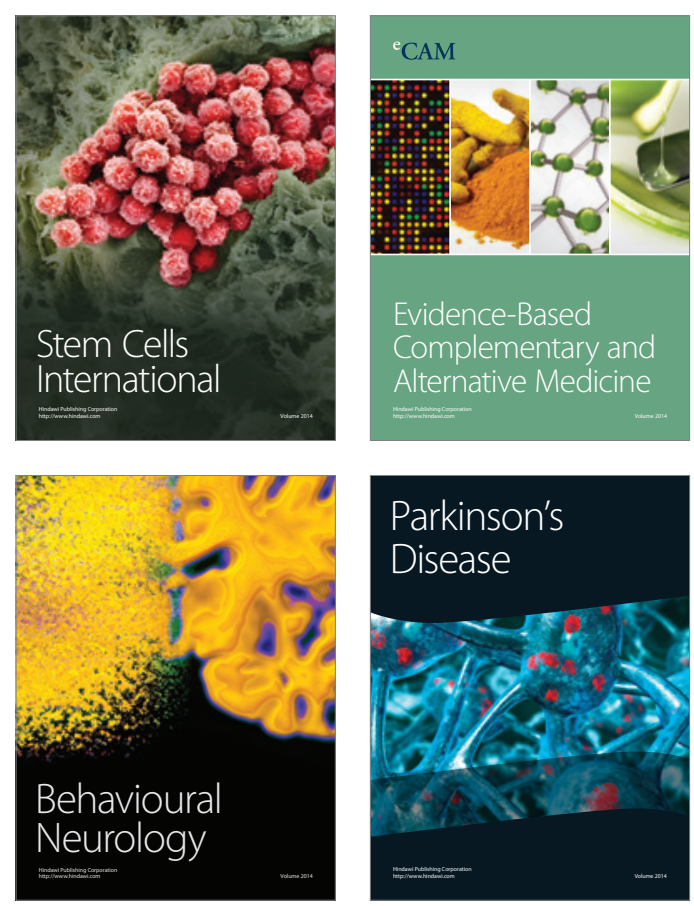

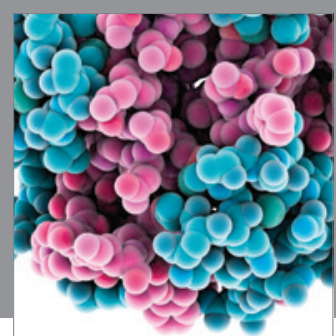

Journal of
Diabetes Research

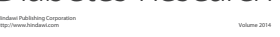

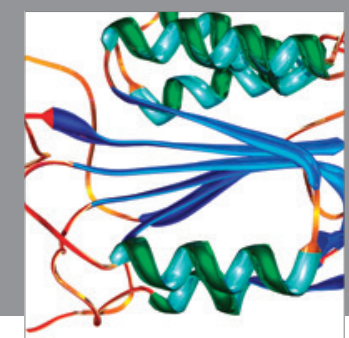

Disease Markers
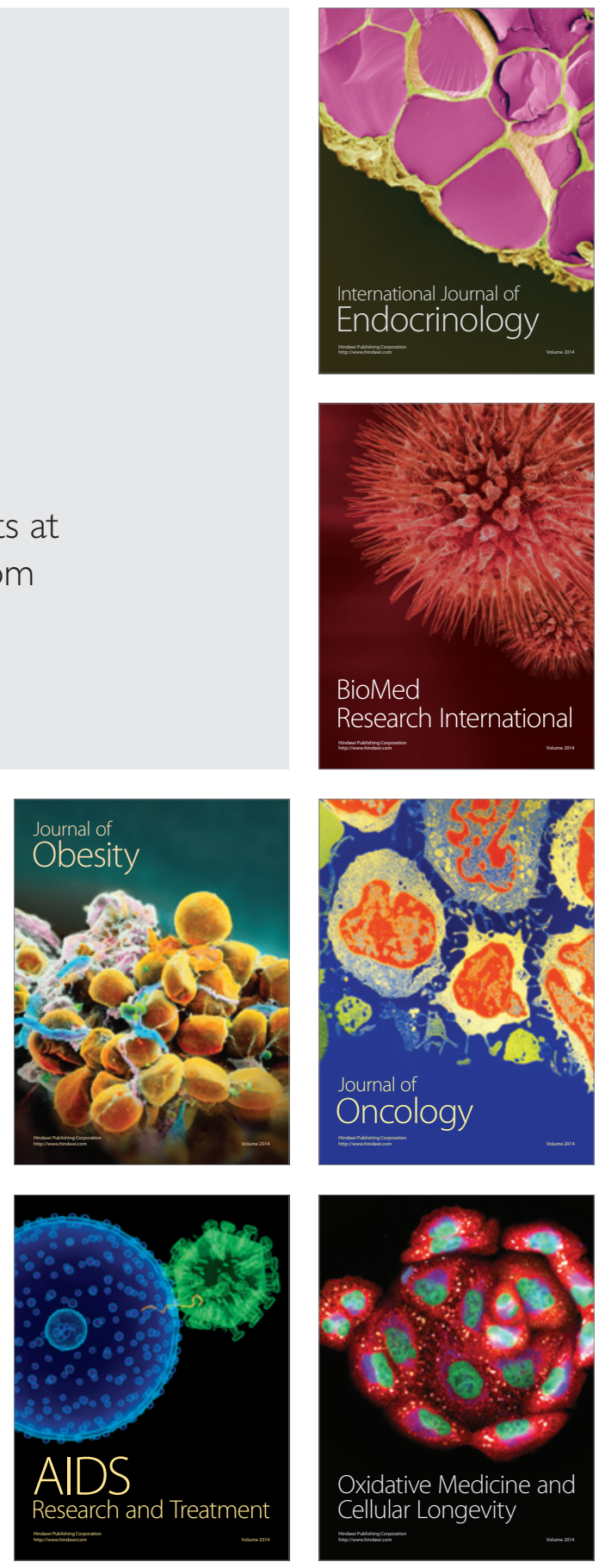